About Us

\title{
Advanced Materials Research
}

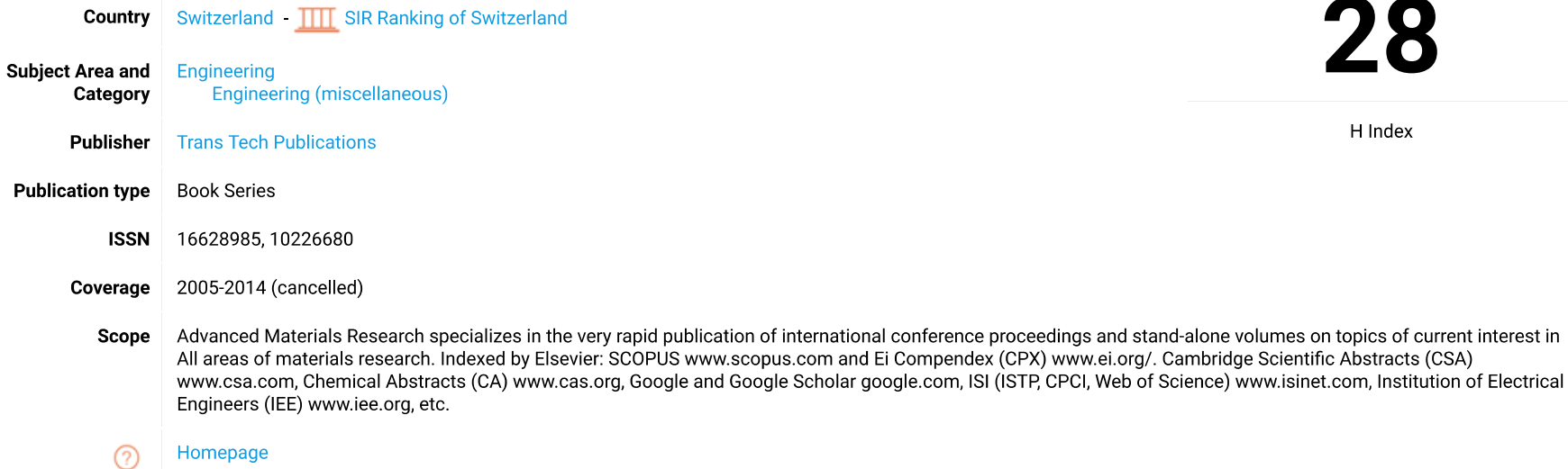

Quartiles

Engineering (miscellaneous)
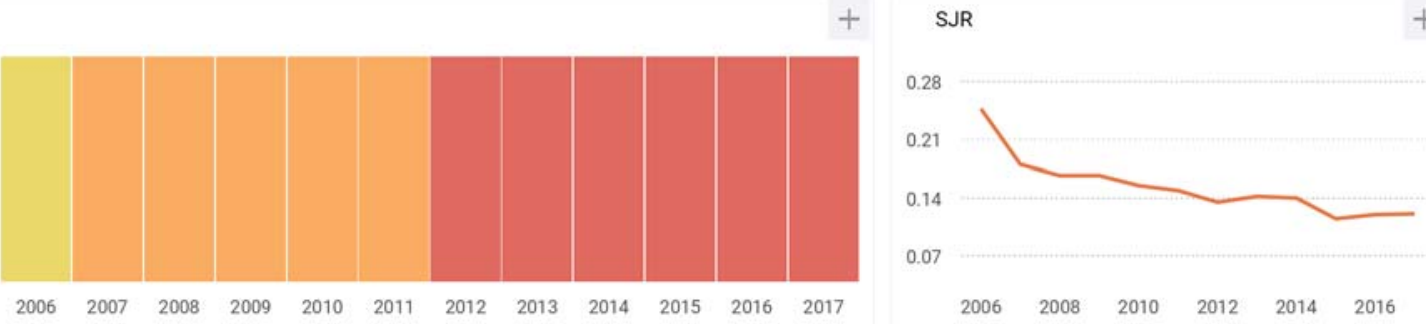

Total Cites Self-Cites

$12 k$

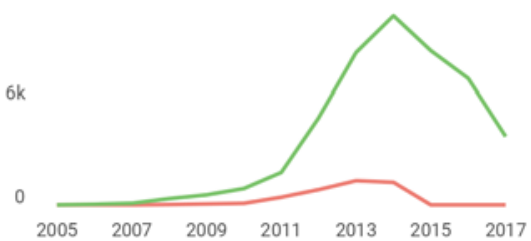

\% International Collaboration

15

7.5

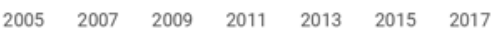

Cited documents Uncited documents

$100 \mathrm{k}$
External Cites per Doc Cites per Doc

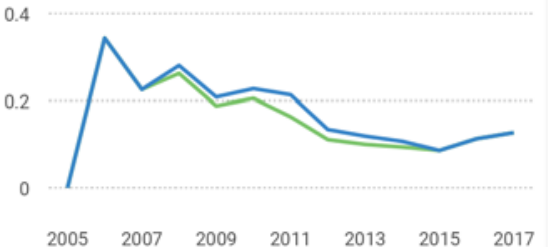

Citable documents Non-citable documents $100 \mathrm{k}$

$50 \mathrm{k}$

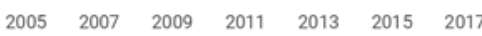

Advanced Materials Research

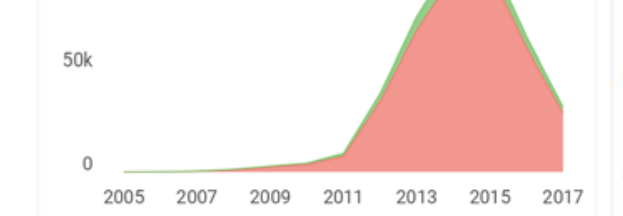

$\leftarrow$ Show this widget in your own website

Just copy the code below and paste within your $\mathrm{html}$ code:

SJR 2017 Engineering (miscellaneous) powered by scimagoir com
Citations per document

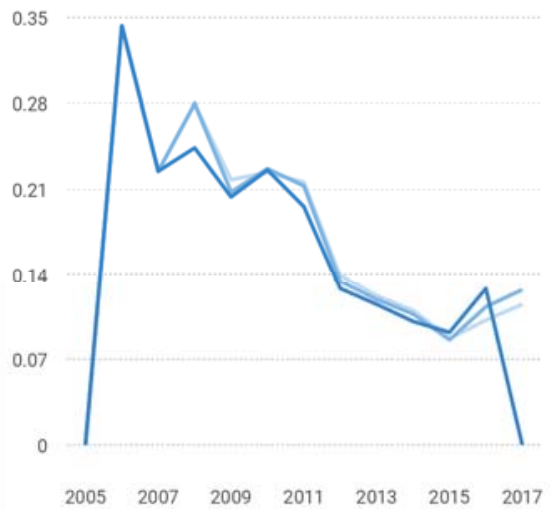

Cites / Doc. (4 years)

Cites / Doc. (3 years)

- Cites / Doc. (2 years) 


\section{ABOUT US CONTACT US}

\section{Periodicals}

\section{Engineering Research}

\section{Advanced Engineering Forum}

Journal of Biomimetics, Biomaterials and Biomedical Engineering

Advances in Science and Technology

Applied Mechanics and Materials

International Journal of Engineering Research in Africa

Foundations of Materials Science and Engineering

\section{Materials Science}

Home Advanced Materials Research Details

\section{Advanced Materials Research}

ISSN: 1662-8985

Volumes My eBooks Details Editorial Board

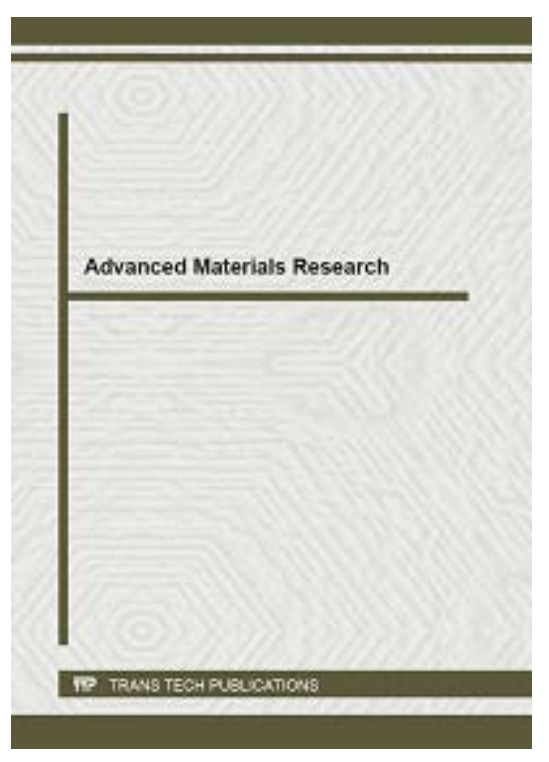

manufacturing.

"Advanced Materials Research" is one of the largest periodicals in the field of materials engineering.

"Advanced Materials Research" specializes in the publication of thematically complete volumes from international conferepmn nmmnndinm nnd nnmmintn special topic volumes papers by individual c
About:

"Advanced Materials Research" is a peerreviewed journal which covers all aspects of theoretical and practical research of materials science: synthesis, analysis of properties, technologies of materials processing and their use in modern 
Journal of Metastable and Nanocrystalline Materials

Journal of Nano Research

Defect and Diffusion Forum

Solid State Phenomena

Diffusion Foundations

Materials Science Forum

Key Engineering Materials

Nano Hybrids and Composites

Advanced Materials Research

\section{Limited Collections}

Specialized Collections

Retrospective Collection

\section{Newsletter Subscription}

Authors retain the right to publish an extended and significantly updated version in another periodical.

All published materials are archived with PORTICO and CLOCKSS.

Authors can share research paper via KUDOS platform to help broaden your audience. Share your work via scholarly collaboration networks (like ResearchGate, Academia.edu and Mendeley) in a fully copyrightcompliant way using The Kudos Shareable PDF

\section{Abstracted/Indexed in:}

SCImago Journal \& Country Rank (SJR)

www.scimagojr.com.

Inspec (IET, Institution of Engineering Technology) www.theiet.org.

Chemical Abstracts Service (CAS) www.cas.org.

Google Scholar scholar.google.com.

GeoRef www.americangeosciences.org/georef.

Cambridge Scientific Abstracts (CSA) www.csa.com.

ProQuest www.proquest.com.

Ulrichsweb www. proquest.com/products-

services/Ulrichsweb.html.

EBSCO Discovery Service

https://www.ebscohost.com/discovery.

CiteSeerX citeseerx.ist.psu.edu.

Zetoc zetoc.jisc.ac.uk.

EVISA

http://www.speciation.net/Public/Linklists/EVISA.html.

Index Copernicus Journals Master List

www.indexcopernicus.com.

WorldCat (OCLC) www.worldcat.org.

ISSN print 1022-6680

ISSN cd 1022-6680

ISSN web 1662-8985

\section{Additional Information:}

Please ask for additional information: amr@scientific.net 


\section{Subscription}

Irregular: approx. 4-6 volumes per year.

Rates 2019 for:

- Web 2019: EUR 588,-,

- Web 'All BackVolumes 2018-till Vol. 1': EUR 57'000,-,

- Print or CD 2019 (+free WEB): EUR 736,- (incl. Postage)

\section{Subscribe}

Subscribe to our Newsletter and get informed about new publication regularly and special discounts for subscribers!

\section{DISTRIBUTION \& ACCESS FOR PUBLICATION SUPPLEMENTS ABOUT US}

\section{POLICY \& ETHICS CONTACT US IMPRINT \& PRIVACY POLICY SITEMAP}




\section{ABOUT US CONTACT US}

\section{Periodicals}

\section{Engineering Research}

Advanced Engineering Forum

Journal of Biomimetics, Biomaterials and Biomedical Engineering

Advances in Science and Technology

Applied Mechanics and Materials

International Journal of Engineering Research in Africa

Foundations of Materials Science and Engineering

\section{Materials Science}

\section{Home Advanced Materials Research Editor Board \\ Advanced Materials Research \\ ISSN: 1662-8985 \\ Volumes My eBooks Details Editorial Board \\ Editor(s) in Chief \\ Prof. Xiao Zhi Hu \\ SEND MESSAGE \\ University of Western Australia, School of Mechanical and Chemical Engineering; Perth, Australia, WA 6009; \\ Prof. Alan Kin Tak Lau \\ SEND MESSAGE \\ Swinburne University of Technology, Faculty of Science, \\ Engineering and Technology; John Street, Hawthorn, \\ Australia, VIC 3122; \\ Editorial Board \\ Peng Cao SEND MESSAGE \\ University of Auckland, Department of Chemical and Materials Engineering; Private Bag, Auckland, New Zealand, 92019;}

We're Online!

How may I help you?

Technical University $\iota$ 
Journal of Metastable and Nanocrystalline Materials

Journal of Nano Research

Defect and Diffusion Forum

Solid State Phenomena

Diffusion Foundations

Materials Science Forum

Key Engineering Materials

Nano Hybrids and Composites

Advanced Materials Research

\section{Limited Collections}

Specialized Collections

Retrospective Collection

\section{Newsletter Subscription}

Environmental Engineering, Department of Materials Science and Engineering; 103-105 Muncii Blv., Cluj-Napoca, 400641, Romania;

\section{Prof. Prafulla K. Jha SEND MESSAGE}

Maharaja Sayajirao University of Baroda, Department of Physics, Faculty of Science; Vadodara, India, 390 002;

\section{Prof. Heinz Palkowski SEND MESSAGE}

Clausthal University of Technology, Institute of Metallurgy; Robert-Koch-Strasse 42, Clausthal-Zellerfeld, 38678, Germany;

\section{Wolfgang Sand $\quad$ SEND MESSAGE}

University of Duisburg-Essen, Biofilm Centre, Aquatic Biotechnology; Geibelstrasse 41, Duisburg, 47057, Germany;

\section{Dr. Ching Hua Su SEND MESSAGE}

NASA/Marshall Space Flight Center, EM31 NASA/Marshall Space Flight Center; Huntsville, USA, 35812; 


\section{ABOUT US CONTACT US}

\section{Main Themes}

Advanced X-Ray

Characterization Techniques

Vol. 620

Hydraulic Equipment and Support Systems for Mining Vol. 619

Sustainable Development of Natural Resources

Vols. 616-618

Advances in Power and Electrical Engineering Vols. 614-615

Progress in Environmental Science and Engineering Vols. $610-613$

Progress in Renewable and Sustainable Energy

Vols. 608-609
Home Advanced Materials Research Advanced

Designs and Researches for Manufacturing

\section{Advanced Designs and Researches for Manufacturing}

\section{Papers Book}

Volumes 605-607

doi: https://doi.org/10.4028/www.scientific.net/AMR.605$\underline{607}$

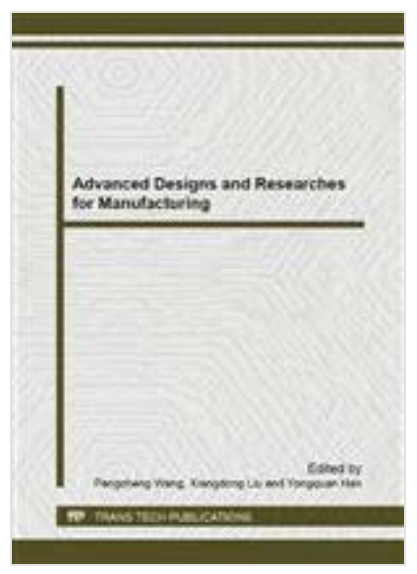

\section{Description:}

Volume is indexed by Thomson

Reuters CPCl-S (WoS).

The studies presented here cover the topics of product design, manufacturing and analysis, management and production scheduling, supply chains, CAD/CAM/CAE, reliability, fault diagnostics and quality monitoring, measurement techniques, technologies and equipment, dynamic analysis of mechanical systems and mechanical transmissions, fluid power transmission and control, mechatronics, industrial robotics, control technologies and intelligent systems, electronic and microelectronic technology, embedded systems, signal and intelligent information processing, software and computers in 
Advanced Designs and Researches for Manufacturing Vols. 605-607

Progress in Materials and Processes

Vols. 602-604

Management, Manufacturing and Materials Engineering II Vol. 601

\section{Advanced Research on Environmental Science and Material Application}

Vol. 600

Advances in Environmental Engineering

Vol. 599

\section{Architecture and Urban} Development

Vol. 598

Advances in Industrial and Civil Engineering

Vols. 594-597 research and engineering solutions.

Review from Ringgold Inc., ProtoView: About 550 papers, selected from submissions, cover product design, manufacturing, and analysis; management and production scheduling; supply chain; computer-aided design, manufacture, and engineering; reliability, fault diagnostics, and quality monitoring; measurement techniques, technologies, and equipment; the dynamic analysis of mechanical systems and mechanical transmissions; fluid power transmission and control; mechatronics; industrial robots; control technologies and intelligent systems; electronic and microelectronic technology; embedded systems; signal and intelligent information processing; and software and computer research and engineering solutions. The three volumes are paged sequentially and indexed together in the final volume.

\section{Info:}

ISBN-13:

978-3-03785-544-7

Editors: $\quad$ Pengcheng Wang, Xiangdong Liu and Yongquan Han

Pages: $\quad 2738$

Year: $\quad 2013$

Edition: softcover

TOC: $\quad$ Table of contents

\section{Buy this volume:}

Print

978-3-03785-544-7

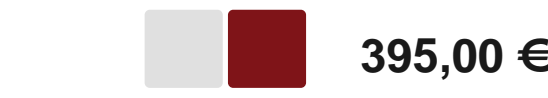

CD

978-3-03795-345-7

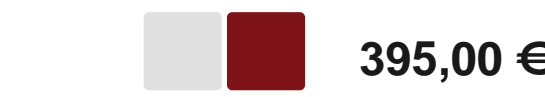

CD+Print* 978-3-03785-544-7

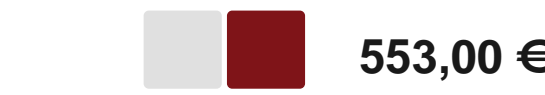


eBook**

978-3-03813-925-6

1

eBook+Print*

978-3-03785-544-7

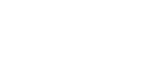

*If you buy CD+Print or eBook+Print, you save $30 \%$

${ }^{* *}$ See an example
$553,00 €$

$395,00 €$

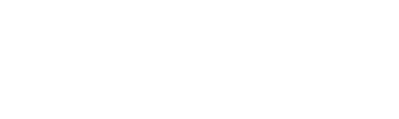

DISTRIBUTION \& ACCESS FOR PUBLICATION SUPPLEMENTS ABOUT US

\section{POLICY \& ETHICS CONTACT US IMPRINT \& PRIVACY POLICY SITEMAP}




\section{Table of Contents}

Preface and Conference Organization

\section{Chapter 1: Product Design, Manufacturing and Analysis}

The Optimization Design of Overhead Traveling Crane's Box Girder

G.F. Tian, S.Z. Zhang and S.H. Sun

Requirement Forecasting of Equipment's Maintenance Spares-Parts Based on Exponential Smoothing Method

X.C. Liu, Y.L. Zhang, A.J. Huang and L.Y. Xu

The Combined-Matching Design of the Tower Body of Tower Crane

B. Li, Y.X. Ke, Z.L. Song and H.D. Liu

To Analyze The Influence Factors on Energy Saving of Hybrid Bus

Y.L. Jiao, Y.P. Li and W.S. Yan

Optimization Design of Shading Shed Transmittance in Highway Tunnel Entrance

G.C. Zhang, H. Bai, H.X. Liu and B.H. Zhang

Application Study of the Virtual Tactile Design in Product Design

X.Y. Suo, R.B. Hu and R.P. Xu

Optimization Design of Stack Package Warpage Based on Moldflow Software

M.X. Zang, T. Wang, C. Liu and Y.R. Zhao

A Parametric Study of the General Profile for Hydrodynamic Journal Bearings

X.P. Pang, S.Y. Wei and K. Niu

The Exploration of Recycling Design of Furniture Products Based on Structure

L. Liu

Application of Improved Genetic Algorithm to Traffic Equipment's Rush-Repair in the Wartime

G.S. Wu and Q.Y. Zhang

Application of Fractal Graphics in Fashion Design

Q.J. Ge, Y.T. Sun and Y. Liu

Design of the Process and Equipment of Melt PEK Filter

X.J. Wu and Q. Qiao

Optimization Design Research on Manual Piston Pump

N. Liu, J.L. Liu, B.H. Fang, H.W. Zhang and W.G. Shao

The Assembly Design of Non-Ball Mills

K.S. Li and Y. Li

Static Analysis of Stator Housing of Screw Drilling Rig

X.W. Sun, J. Wang, K. Wang and X. Feng

Design of Non-Ball Mill Based on the Green Conception

K.S. Li and Y. Li

Thermal Design and Simulation for Lithium-Ion Power Battery Pack Assembly

Z.J. He, X.J. Hu, S.Z. Di, B.B. Song and C.F. Yang

Preliminary Perform of PDM Technology in Automotive Design

H. Zhou

Research on Storage Life of Electronic Equipment Based on Goodness of Fit Test Method J.S. Wang, J.H. Wu, Y.D. Wang and J.W. Lei

Optimizing Design of New Kind Acoustic Horns for Ultrasonic Machining Based on FiniteElement Method

X.H. Zhang, J. Gao and K.X. Zhang

Research of a Variety of Fuel Injection Timing Control Experiment Station for Automotive Engine

J.H. Zhang, M.F. Shou and L. Shi

Virtual Shaping Design of Electrically Driven Hunting Cart

Q.L. Du, X.W. Jiang and Z.X. Cheng 
Application of Advanced Materials in Sports Engineering

Y.T. Cai and Z.Q. Song

A New Design Approach for PSS Conceptual Development

L.J. Yang, K. Xing and S.H. Lee

The Analysis of the Fly Shear Head Motion Track

J.L. Shi, C.Q. Zhu and M. Zhao

Innovative Design of Portable Public Transport System for University Students

J.H. Xu

Appearance Design Research of Home Sealing Machine for Bagged Food

L. Pan, X.C. Cheng and Q.L. Du

The Gate of General Top-Open Freight Train Security Investigation

R. Gou and T. Huang

The Application of Gray Clustering and Information Axiom Integrated in the Scheme

Evaluation of Mechanical Products

J.W. Qiu, R.J. Zhang and X.X. Si

Application of Accuracy Engraving Technique in the Complex Curved Surface Mould Processing

X. Liu and W. Fan

Collaborative Optimization on Structural Parameters of Scroll Compressor

T. Liu, H.W. Sun, Z.X. Wu and M.H. Xu

Single Inlet Pressure Swirl Nozzle Stationary Wave Pattern and Quality Optimization

J.L. Wu, D.Y. Zhang, X.G. Jiang and J.L. Lv

Application Boundary Element Method to Compute the Potential of the Eight-Needle Electrodes

A.L. Wang and F.P. Liu

Thermal Layout Optimization of Stacked Chip Based on Ant Colony Algorithm

J.G. Jiang, Q. Su, L.F. Shi and W.D. Xu

Developing Size Specifications of 3D Body Models for Males Aged between 7 and 18

Y.L. Choi

Assembly Line Balancing the Comparison of COMSOAL and MSNSH Technique in

Motorcycle Manufacturing Company

A. Lerttira and P.K.D.V. Yarlagadda

A Novel Roller Chain Sleeve Crevice Identification and Orientation Device Design and Test

S. Ding, X.L. Liu, Y.B. Zhang, J.J. Liu, G.Y. Zhu and P. Wang

Study of Wheat Straw Weaving Process and Decorative Effect

B. Liu, F.H. Wang, F. Liu and J.P. Sun

The Analysis on Motion in Quiescence of Packaging Container Molding

X.Z. He, D.Z. Liao and X.J. Xiong

Robust Design of an Ultra-Thin Centrifugal Fan on Fuzzy-Based Taguchi Method

K.H. Hsien and S.C. Huang

Research on Key Technologies in the Field of Wood Saving and Substitution in Packaging of Electromechanical Products

S.W. Su, A. Chen and H.Q. Yang

Inverter Based on Improved Z-Source Structure for Off-Grid Type Wind Power

Generation

X.G. Wang, Z.Y. Zhao and G.Q. Cao

Structure Design and Modeling for a Picking Bananas Manipulator

H.J. Wang, G.G. Huang, J.X. Chen and X.J. Zou

Reinforced Techniques Analysis of Goaf-Side Entry at Isolated Island Coal Face Based on

FLAC Numerical Simulation

W.H. Zha

Design of the Spring Fixture for Aging Treatment

N.W. Wang and Z.C. Huang

A Framework for Life Cycle Cost Estimation of a Product Family at the Early Stage of

Product Development

J.S. The, P.K.D.V. Yarlagadda, M.A. Karim and C. Yan

Design of a Type of Semi-Automation Stretcher-Vehicle

J.C. Dong, Y. Yang, Y.J. Li and C.T. Song 
Marine Oil Spill Emergency Response Research

F. Yu, X.F. Sun and X.Y. Zhang

Design and Kinematic Analysis of a New Grapple Mechanism

F. Deng, J.B. Chen, M. Chen and F.J. Peng

Classification of Men's Shoulder Shapes Based on Pyramid Method

M.H. Cui, Y.L. Choi and Y.J. Nam

Extraction of Design Factors of Product Family Based on Customer Needs

M.N. Ni, Q.Z. Lv and P. Jin

Strength Finite Element Analysis and Test Research of Steel Package Rotation Table Beam and Tumbler

J.Q. Liu and H.Y. Liu

Fuzzy Information Axiom in Conceptual Design Scheme Evaluation of Handling

Equipments

Q. He, R.J. Zhang, N. Guo, D.S. Cong and J.W. Qiu

Test Research on the New Electromechanical Axial-Flow Pump with Advantages of Small

Vibration and Noise

B. Fang, Q.D. Zhou, J.B. Xie and M.Z. Qiao

Innovation Design Method of Product Base on Materials Innovation Technologies

Y. Guo and X. Shi

Study On the Design Methods of Fast Moving Consumer Goods

M.N. Ni, L. Wang and Y. Li

Intelligent Design of Mechanical Products Based on Function-Knowledge-Structure

F. Cao

Development of Parts Family Manage System Based on PDM in Large-Scale Air Separation Equipment

R. Zhu, G. Meng and H.G. Li

An Efficient Torlerance Robust Design Method Based on Taguchi Theory

H.M. Kan, H.B. Li, X.L. Xia and Y.T. Zhang

Research on Electric Power Equipment Preventive Maintenance Cycle on the Basis of Economic Life Cycle Costing

Y. Li, Y.M. Hu, Y.F. Luo and C.C. Liu

T91 High Temperature Reheater Piping Leakage Analysis

Y.J. Niu, L. Song, F.T. Hu and K.F. Wang

Accessories' Matching Design Study and Development

X.Q. Yu, L.X. Fan, H.X. Zhang, Y.X. Chen, P.L. Yang and Z.F. Wang

Evaluation Model of Aircraft Maintenance Mode Based on Improved AHP

J.S. Chen and C. Liu

Design and Realization of Hand-Held Smart Electrothermal Umbrella Applied New

Materials

P. Gao, Y. Ping and G.J. Han

Research on Individualized Requirement Modeling Oriented to the Dynamic

Synchronization

Q. Yang, D.Z. Wei, W. Tang and Y.F. Zhu

The Research and Application of Seeding Machine's Dislocation Type Seeding Device

R. Wu, Y.K. Xu and S. Xue

Design of a Kind of Drilling Machine for Semicircle Shaft

W.M. Yang, S.X. Zhao, P.F. Zheng and Z.X. Lou

Stability Analysis of Pumper and Finite Element Analysis of Ladder Structure for a Scaling Ladder Pumper

W.M. Yang, L.J. Pan, J. Lv and X.L. Deng

A Novel Approach to Evaluate the Stability of Production Manufacturing System Based on Petri-Net and Analytic Hierarchy Process

H.X. You

Research and Design of a Novel Mobile Police Station

X.Y. Zhao, X. Yuan and Y. Lou

Design and Simulation of Visual Miniature Loop Heat Pipe

Y. Chen, Y. Qu and S.S. Zhang 
Improvements in Manufacturing Processes in a Graphical Analysis as Result of Kaizen Events

B.T. Rieger and M. Sebastián

A Comparison Study of Small Displacement Torsor and Analysis Line Methods for

Functional Tolerance Analysis

C.L. Li, J.X. Yang, J.Y. Wang and W.X. Ma

Ontology-Based Knowledge Representation for Mechanical Products

J. Li, Y.B. Yang and L.F. Wei

The Conceptual Design of Table Jaw Based on Functional Principle Design

J.Y. Zou

The Tolerance Optimization Design of Displacement Pump

C.Y. Li, C.D. Ji and K. Ding

Customer Evaluation and Selection Method of Real-Time Innovative Design Based on the

Network

J.S. Luo, B.G. Wang, X.L. Wang and H. Cheng

Study of Regenerative Braking Model and Simulation of a Car

F. Wang and Y.H. Wu

DFSS of a Diagonal Impeller

X.X. Luo, X.X. Cai, G.S. Wang and D. Mi

A Fast Point-Sampled Model Denoising Algorithm for Product Design

Y.S. Li

The Finite Element Analysis on the Crossbeam of Full Automatic Hydraulic Tile Press

D.Q. Lv

Optimization of Micro Wind Turbine for Dental Fiber Handpiece Based on the Taguchi

Method

K.H. Hsien and S.C. Huang

Stress Analysis of the Adhesive Used in a Hard Disk Drive Bearing Assembly Using Finite Element Model

$\mathrm{P}$. Vengsungnle and K. Tangchaichit

Innovative Design of Hydraulic Driving Drum for Belt Transfer Machine

X. Zhang, Y.B. Hou, J.H. Yuan and C.Q. Sun

Study on the Novel Spinning Technology of Broken Silk Fancy Yarn

Y. Huang, J.Y. Zhong, J. Chen, L.L. Yang, X. Chen and H.L. Yi

An Investigation on Development of Seat Cooling Fan for Vehicle

J.H. Kim, J.M. Seo and I.S. Jung

Design and Research on Wind-Solar-Diesel Hybrid Generating System at High Altitude

L.B. Mao, W.J. Wang, B. Yi, Q. Dai, H.J. Mi and T. Yuan

A New Cast Stone Roller Kiln and its Combustion Control Approach

J. Chen, A.J. Luo, Y.X. Yuan, C. Xiao, W.L. Wang, Z.X. Li, H.C. Li, B.P. Mao and Z. Chen

High-Efficiency Solar Power Supply Design

H. Yang, W.Q. Huang, Z.F. Wang, L.G. Chen and Y. Yin

Simulation Research about Web Press Paper Tape the Second Time Tension Control Based on MATLAB

Y.Q. Sun

Research on Ride Comfort of Nonlinear Vehicle Suspension

Z.Y. Zhao, Z.H. Fan, J.J. Zhang and Z.Q. Xia

Collaborative Design Optimization of Main Movement System of Hydraulic Piston Engine

D.L. Xue, H.X. Zhang and Y. Liu

Study on Torque Converter with Adjustable Guide Vanes of Hydrodynamic Speed-

Adjusting Wind Turbines

W. Cai, W.X. Ma, C.B. Liu and W.W. Du

Analyzing on the Principles of Intelligent Furniture Design

G.Q. Zhang and J.J. Zhang

Analysis of Fabric Reconstruction Problem in the Apparel Production Design and

Manufacture

C.Y. Wu, Y.J. Zhang, C.F. Qu and L.B. Xu

Pilot Investigation on the Driving Posture Comfort among Malaysian Drivers

M.S.A. Hussin, R.A.R. Ghazilla and M. Widia 
Product Style Map - An Effective Tool for Product Strategy Planning

T. Han and S.Q. Sun

\section{Chapter 2: Management and Production Scheduling}

Research on Exhibition Logistics Information System Designing

S.X. Zhang

The Intelligent Forecasting Method of Mine Equipment Maintenance Plan

W.X. Huang

Flexible Job-Shop Scheduling Problem under Uncertainty Based on QPSO Algorithm

F.S. Pan, C.M. Ye and J. Yang

Information on Risks and Prevention of the Supply Chain in E-Commerce Environment

P.Y. Xu

The Architecture for Solving the Cross-Domain Keywords During New Product

Development

Y.C. Tsao, K.C. Hsu and Y.T. Tsai

Spare Parts Production Planning Model Based on Fuzzy Programming

X.Y. Zhang, C. Liu and N.Z. Yang

Value Chain Theory and its Application in Steel Enterprises

W. Dou, J. Shi and J.X. Wei

Business Process Management for Information System Implementation in Discrete

Manufacturing Workshops Based on Multi-Agent Simulation

S.Y. Zhang, Y.Q. Tan and T.H. Zhang

Research on Confidence Degree of Enterprise Alliance under the Environment of NetworkBased Manufacturing

X. Zhang

Scheduling to a Common Due Date on Unrelated Parallel-Machine with Deteriorating Jobs C.J. Hsu

The Research of Heuristic Algorithm for Flow Shop Scheduling Problem

D. Tang and H.P. Shu

Research on the Application of Operation Characteristic Curve in the Sampling Inspection for Foods in Prepackages with Fixed Content

L.X. Zhu, P. Lu, J.H. Wang, Z. Yin and J.X. He

Study on Coal Lean Mining Theory and Practice

Z.X. Liu

A Multi-Issue Negotiation Based Task Allocation in Virtual Enterprise

N.S. Hong and G.Y. Zhang

\section{Chapter 3: Supply Chain}

Introduction of IOT Technology in a Logistic System for High-End Wine Sales

H.D. Zhao, G.N. Liu, Q.Q. Guo, S.G. Ma, Y. Tie and C. Li

Study on Supply Chain Performance Evaluation Method of Equipment Spare Parts

H.Q. Gu, H. Song and C. Zhang

Optimization of Port Supply Chain Super Network under Electronic Commerce

H.Y. Xie, X. Liu and D.P. Zhao

Study on Chinese Container Associates and its Construction Strategy

S.L. Chen, Q.F. Wu and J.J. Sheng

Energy-Saving Technologies of WSN

R.M. Zheng

Study of Container Transport Planning Model and Algorithm

X. Zhang, J.S. Lin and Z. Zhao

Modeling and Optimization of Traceability System for Agriculture Products Supply Chain

F. Li, Y.P. Zhu and H.R. Wu

Design of Manufacturing Logistics Service Platform in a Certain Area

H.L. Zhao 


\section{Chapter 4: CAD/CAM/CAE}

To Solve Mechanical Working Space by Applying Graphic Integration in ADAMS R.H. Zhang, Y.F. Zhu and S. Yang

A Rapid Design System for the Transmission System of Mounter Worktable Based on Second Development of SolidWorks

X.M. Li, W.H. Lu, X. Ning, G.C. Jin and T.C. Yu

Model and Finite Element Analysis of a Bus Body

F. Wang and Q.M. Fan

Optimization Design of a Bus Body Frame

F. Wang and Y.H. Wu

Modeling Method and Application in Digital Mockup System towards Mechanical Product

H.Y. Zhang and J. Li

The Application of AutoCAD Software in Forestry

L.J. Zhao, F.R. Li and W.W. Jia

A New Way of Virtual Prototype Design and Analysis for Tractor Steering System

X.Y. Tang, D. Xiao, L. Liu, E.R. Mao, Z.H. Song and Y.K. Peng

Offshore Platform Deck Crane Fatigue Analysis Based on Abaqus

S.Y. Wang, Q. Mei, L. Liu and Y.Q. Zheng

Simulation of Crank-Rocker Mechanism on Finite Element by ANSYS

X.Y. Zhang

Characteristic Study on Temperature Field of Hydrostatic Bearing of Hydroforming

Machine

S.G. Wang, X.F. Du, D.S. Li and Q.M. Hu

Study on the Design Method of Testing Fixture for Bent Tube Based on UG

X.J. Zhao, G.B. Pang, C.F. Yuan, M.J. Zhou and S. Li

Parameterized Modeling of Circumferential MEFP Warhead Based on Characteristics Z.G. Liang, J.W. Jiang and T.G. Zhang

Research on the Virtual Assembly-Disassembly and Repair of the Automobile Drive Axle H. Sun and W.G. Deng

3D Modeling and Motion Simulation of Single Surface Corrugated Machine Based on SolidWorks

M.X. Yan

ANSYS Application in Modal Analysis of Bus Body Frame

L. Xu

656

Calculation of Tilting Torque for Converter Based on Solidworks

H. Guan and X.P. Ren

A Single-Phase Electric Harmonic Monitoring System Design Based on the LabVIEW

Z.J. Zhang

664

Optimization and Application of STL Model Slicing Algorithm in Rapid Prototyping

C.X. Wang and Z.H. Li

Motorcycle Modeling with SimMechanics

H.D. Wu and H.B. Xu

System Dynamic Characteristic Simulation of Spacecraft Propulsion System Based on AMESim

Z. Yan, X.H. Peng, Y.Q. Cheng and J.J. Wu

Study on Parametric Assembly Modeling of Standard Parts with Assembly Level of Mold Based on UG Secondary Development

M.J. Zhou, J.C. Zhang, X.J. Zhao and Q.Y. Ma

ANSYS-Based Finite Element of Rear Frame in Underground Transport Vehicle

L. Sun

\section{Chapter 5: Reliability, Fault Diagnostics and Quality Monitoring}


Research on Intelligence Inspections of Gear Profile Deviation

H. Zhang, Z. Xu and W. Fu

Research on Reliability Qualification Test of Mechanical and Electric Equipment Onboard Z.R. Xie, J.W. Lv and Z.H. Liu

Research on Fault Diagnosis for Bearing of CNC Machine Tools

B.C. Zhang, X.J. Yin, Z.J. Zhou and Y.L. Zhang

Multiple Reference Impact Testing for Bridge Assessment with Drop Hammer

Y.J. Liao, Y. Zhou and P. Qin

An Independent Component Analysis Based Defect Detection for the OLED Display

Z.L. Wang, J. Gao, C.X. Jian, Y.C. Liang and Y. Cen

Fault Diagnosis of Valve Train of Internal Combustion Engine Based on the Artificial

Neural Network and Support Vector Machine

F.R. Bi and Z. Song

A Note on the Early Failure Period for CNC Machining Tools

Z.C. Jia and Z.J. Yang

High Order Spectrum Characteristics of the Elevator Fault

Y.K. Zheng and Y.J. Huang

Field Test of Wellbore Anti-Collision Monitoring System

G. Liu, Q.Z. Yang and B.S. He

The PHM Research of Vessels Equipment Based on Condition

C.J. Wang, Y.Z. Liu and H.J. Fan

Large Pendulum Shaft Failure Analysis and Countermeasure Research

W.M. Lin, Y. Zhang, H.Y. Xiang and Z. Li

Electromagnetic Nondestructive Testing in Cracked Defects of Oil-Gas Casing Based on

Ant Colony Neural Network

W. Zhang, Y.B. Shi and Y.J. Li

The Research and Analysis on Valve Reliability of Reciprocating Compressor

J.Q. Jin, G.L. Sui and H.T. Zhang

The Reliability Estimation of Double-Parameter Exponential Distribution on Zero-Failure

Data

J.M. Zhong and H.Y. Zheng

Application of Measurement System Analysis in Controlling the Gun Maintenance Quality M. Zhang, S. Wang, G.D. Wang and W. Jiang

Research on Parameter Distribution of Interval Deleted Data with Turnbull Estimation

J.H. Wu, J.S. Wang, H.B. Liu and J.W. Lei

Stress Analysis of Ultra-Supercritical and Electrical Three-Way Valve Body Intensity in a

High Pressure Heater Using FEM

S.X. Li, J.H. Hu and L.C. Li

Credibility Measure and Assessment Method of Equipment Severity to Voltage Sag

X.N. Liu, Y. Wang and X.Y. Xiao

Discussion about Circuit Board Fault Diagnosis Based on D Algorithm

X.Q. Xing and Z.T. Yao

Research on Fault Diagnosis Based on TEAMS

Y.H. Liang, Q.Y. Wu and D. Jin

Mechanism Movement Reliability Analysis of Galting Gun

X. Han, Y.C. Bo, Q. Li and Y.J. Guo

Sensitive Equipment Failure Assessment Caused by Voltage Sags Using Interval Probability H. Li, X.Y. Xiao and Y. Wang

Tooth Surface Contact Fatigue Reliability Analysis of Cycloidal Gear Based on Monte-

Carlo

T.M. Guan, J.B. Li and L. Lei

Fault Location for Transmission Line with Shunt Reactors

X.D. Liu, R. Guo and R.M. Zeng

Impacts of Protection Cooperation on Voltage Sag Frequency and Sensitive Equipment Trips 
Fracture Reason Analysis for Helical Gear Shaft of Converter Tilting Mechanism Senior Reducer

L.K. Guan and N.N. Wang

Fault Diagnosis System of the Fire Control System Based on Fuzzy Neural Network

P.J. Zhang, Y.C. Bo, H.Y. Wang and Q. Li

The Fatigue Life Research on the Crossbeam of Automatic Hydraulic Tile Press

Y. Pan

The Fault Diagnosis Model of FMS Workflow Based on Adaptive Weighted Fuzzy Petri Net

H.L. Pan, W.R. Jiang and H.H. He

Safety Analysis and Design of Wireless Monitoring System

B. Qian and H.Y. Zhang

\section{Chapter 6: Measurement Techniques, Technologies and Equipment}

Recognition of Branch Insulation Parameters in Coal Mine Distribution Network using Least Squares Method

J.W. Zhao

Application of Sliding Window-Genetic Programming Algorithm in Alert and Forecast for Mine Safety Monitoring

R.H. Ma, X.H. Dong and J.L. Wang

Camera Calibration of Binocular Vision Based on Virtual 1D Target

Y.B. Guo, G. Chen, D. Ye and F. Yuan

The Electronic Measuring System Design of Identifying Freshwater Fish Meat with

Different Freshness

X.J. Yang and Z.H. Yan

\section{Chapter 6: Measurement Techniques, Technologies and Equipment}

A Low Frequency and High-Precision Microbarograph Monitoring System

L. Li, Z.H. Zhou, C.X. Lv, B. Liu, H.C. Zang, P.Y. Yao, J. Yuan and Z.L. Hua

Research on Key Technologies of the Needle Loom Condition Monitoring System

H. Deng, B.T. Song, H. Liu, H. Zhang and S. Yang

Determination of Multi-Element in Egg of Poyang Lake Anas platyrhynchos by ICP-AES Y.G. Tu and Y. Zhao

Method of Disease Diagnosing Based on SVM and Rough Set

B.L. Liu and L.X. Gao

The Design of Pressure Meter Based on Ultralow-Power Consumption Technique

Z.Y. Xie, L.P. Zheng and H. Zhang

Road Load Spectrum Collection and Analysis of AMT Actuating Mechanism

X.H. Zou, K. Qiao and X.H. Shi

Research on the Computational Algorithms for Layer Wound Linear Variable Differential Transformers

L. Jiang and G. He

Classification of Floral Origins of Honey by NIR and Chemometrics

X.Y. Liang, X.Y. Li and W.J. Wu

Modeling and Simulation of the Dissolved Oxygen Monitoring System in Aquaculture

D.Z. Huang

Researches on the Size Measurement of Mechanical Parts Based on Image Processing

H.J. Dong, H.J. Yang and G.H. Han

Feature Extraction of Leaf Images for Mite Disease in Cotton Fields

Z.H. Diao, Y.M. Song, Y.P. Wang and H. Wang

Research of Ultrasonic Flow Detection Method Based on Hydrodynamics Analysis L.J. Sun, M.L. Liu and Y. Hou

Research on Non-Invasive Measurement of Optical Parameters of the Tissues by Support Vector Machine 
Determination of Trimethylamine in Air by Cataluminescence-Based Gas Sensor

K.W. Zhou, C.X. Gu, X. Li, D. Su, H.Z. Yang and X. Shen

Monitoring and Research of Power Ultrasonic Honing Vibration Frequency

X.Q. Xing, C.Q. Gao and X.J. Zhu

Granary Temperature and Humidity Detection System Based on MCU

L. Jin and T. Zhao

Flow Rate Measurement Method and Apparatus of Thick Pastes

S.Y. Zhang, Z.N. Wang, X.D. Hao and M. Wu

Principle Error Analysis of Three-Point Supporting Type Barycenter Measurement System Y.X. Hao, Y.H. Liu, S.W. Yang and H.T. Cheng

Design of Data Acquisition and Storage System for Digital and Analog Signal Based on FPGA

H.L. Wang, H.R. Wang and H.F. Ding

Study on the Attenuation Behavior of Acoustic Wave in ER Fluid

N.H. Yu and J.J. Fan

An Measuring and Evaluation Method of Coaxiality Error for Large-Scale Holes

W.J. Xie

964

Vehicle Braking Efficiency On-Line Monitoring and Evaluation with MFDD

W.L. Li, W. Zhou and L. Gao

968

FEM Study on the Dynamic Effects of CMM Geometric Errors

Y.L. Chen, Y.N. Peng and Z.H. Wei

Design of Measurement System for Solid Propellant Kneading Machine's Pot Temperature X.L. Jin, S. Chen and B.J. Ma

Sizing System for Automatic Construction of Dress Shirt Patterns for Men

Y.L. Choi

Structural Damage Detection of the Simple Beam Based on Responses Phase Space

C. Cheng, Z.H. Nie and H.W. Ma

Wheat Sedimentation Value Determination Based on Near Infrared Spectroscopy

L.J. Sun, M.L. Liu, L.L. Xu, X.F. Li and X.D. Mao

Automatic Identification of Crack in Ultrasonic Infrared Imaging

F.Z. Feng, C.S. Zhang, Q.X. Min and P.C. Jiang

The Curing Residual Strain Monitored by Fiber Bragg Grating Sensors

H. Tian, C.S. Ye and X.T. Bao

The Design and Implementation of the Terminal in a Vehicle Exhaust Real Time Detecting System

F. Lin, J. Yan, Z.Z. Ye, Y.J. Song and H.Y. Chen

A Test of Mtem' Application in the Iron Mine ahead to Explore the Water

X.H. Liu, P.S. Zhang, L.H. Sun and S. Chen

Research on the Utilization of Smart Meters' Information under the Background of Smart Grid

H.C. Guo, D.X. Niu, J.P. Liu and Z. Ma

A Sinusoidal Grating Design and Performance Analysis

B. Zhou, Z.Y. Liu and L. Rao

Method of Dynamic Detection for Clutch of Real Vehicle Based on RFID Technology

L.H. Yu and L.R. Wang

Research on Aerocraft Attitude Testing Technology Based on the BP ANN

Z.J. Liang and T.H. Ma

Research and Application of Portable Real Protection Potential Measurement System of Buried Steel Pipeline

X.F. Zhao

Application Research on Aqua-Sim for Underwater Acoustic Sensor Networks

T.Q. Liu, G.J. Han, C. Zhu and C.Y. Zhang

The Insights of Node Deployment for Localization Accuracy in Underwater Acoustic Sensor

Networks

C.Y. Zhang, G.J. Han, C. Zhu and T.Q. Liu 
Determination of Residual Organic Solvents in Antitumor di-phenyl-di-(2,4dichlorobenzohydroxamato)tin by Capillary Gas Chromatography

L.L. Miao, Y.E. Li, Y.L. Li and Q.S. Li

The Design of Real-Time Power Detection System in Communication Equipment

X.J. Yi, J.X. Jiang, D.W. Guo and D.F. Zhang

1063

Research on Frequency Conversion Selective Measurement and Error Correction

Algorithms in Grounding Characteristics Measuring System

S.Q. Wang, X.W. Chen, Z.J. Guo and X. Wang

1068

Identification Research on CMP Multi-Zones Pressure System

Y.W. Wen, X.C. Lu, H. Zhang, K. Zhou and P.Q. Ye

1074

Measurement of Spacecraft Simulator Motion Parameters Based on Multi-Vision System

Y.B. Guo, H.P. Ma, Q. Xia, G. Chen and F. Yuan

1080

The Radius of an Ultrashort Pulsed-Laser to Fresnel Diffraction of a Serrated Aperture

H.S. Wang

1085

Study on the Online Dynamic Weighing System of Heavy Duty Apron Feeder Based on

Labview

Q.G. Deng, H. He and B. Hu

1089

A Least Square Solution for Energy-Based Source Localization in Sensor Networks

N. Jiang and W.B. Ai

Design of the Time Interval Generator Automatic Verification and Management System

Y.J. Fu and X.B. Hou

1099

A Height Estimation Method Based on Joint Time Delay and Phase Estimation for

Wideband InSAR or InSAS

S. Zhang, J.S. Tang and H.P. Zhong

\section{Chapter 7: Dynamic Analysis of Mechanical Systems and Mechanical Transmissions}

A Study on Drive Capstan Stiffness of Cable-Driven Picking Manipulator

H. Luo, Y.G. Tang and J. Shen

Structural Vibration Control of the Magnetic Flywheel Based on GA-PID Neural Network

H.Y. Fu, P.F. Liu, Q.C. Zhang, G.D. Li and D.B. Dong

Dynamic Analysis of Variable-Step Feeding

P.F. Chen, J.F. Cai and S.B. Xu

Vibration Characteristic Similarity Appraisal of Conticaster Vibration Table

W.Z. Yang, Z. Cui, X.P. Ren and F.Q. Su

The Abnormal Vibration Source Analysis of Automobile Drive Axle

C.H. Yang, N.C. Guo, H.S. Song and W.K. Shi

Study on the Non-Linear Dynamic Stability of a Cracked Rotor System

S.Q. Lv, L. Tian and G.W. Zhao

Enclosure Active Structure Acoustic Control Based on Multi-Agent System

Z.C. Li, L.N. Gu and N. Chen

Effect Factors Analysis of Flow Generation Noise from Muffler Element with Inserted Tube H.J. Zhao, H.X. Wang, J.D. Chang, Q. Li and L.P. Tian

Study on Impact of Powertrain Mounting Stiffness on Vehicle Vibration Characteristics Y.Z. Men, H.B. Yu, H. Wang and L. Xu

Research on Influence of Intertooth Space Confriction to Transmission Efficiency under EHL

W.H. Liang, K. Liu, X.L. Liu and Y.H. Cui

A Vibration Analysis and Evaluation System Construction Based on On-Line Inspection Y.C. Xia

Vibration Transfer Analysis of High Speed Train Considering Car body Flexibility

T.L. Chen, J. Zeng, Y.H. Lu and L.M. Zhang

Dynamical Analysis for Mechanical Arm of the Coal Sampling Machine Based on RigidFlexible Coupling Model

L.L. He and R.L. Li 
A Modal Analysis of Eccentric Shaft of Caster Vibration Device

J.L. Shi, X. Yang and D.D. Ma

The Development of Structure Random Vibration Parameter Analysis Tool Software under Hot Environment Condition

G.Q. Wu, X.L. Han, J.M. Du, L. Li and C.M. Hu

Virtual Prototype Modeling and Dynamic Simulation for a Large Pendulum

W.M. Lin, Y. Zhang, H.Y. Xiang and B.A. Han

Study on Dynamic Simulation of Hydraulic Die Forging Hammer Based on VPT

Y.J. Zhang

Research of Dynamic Performance of Reciprocating Compressor Valve

J.Q. Jin, G.L. Sui and D.Y. Shen

Vibration Modal Analysis of the Upper Frame of Hydraulic Excavator

C.P. Zuo, Y.Q. Zhou, R. Huo, L. Wang and H. Li

Analysis on Structure Stress Characteristics of Top and Low Slewing Frame of Tower

Crane

B. Li, H.D. Liu, B. Cai and Z.L. Song

Analysis of Local Stress and Vertical Deflection of Down Chord of Inverted Triangle Cargo

Boom of Tower Crane

B. Li, Z.L. Song, Y.X. Ke and H.D. Liu

The Design of Transmission Scheme of the 6-Speed Automatic Transmission Based on the 01N Automatic Transmission

M.F. You, Q. Wen, M.F. Zheng and Z.W. Li

Analysis on Dynamic Characteristics of Paper Feeding Device

Y. Huang, J.F. Cai and R. Xie

Dynamic Simulation and Analysis of a Dual-Link Suspension

J.Z. Feng, L. Liu, S.L. Zheng, D.W. Gao and T. Sun

Dynamic Performance Analysis for Milling Head Box of Spiral Drill Collar Machine

K. Wang, Y.X. Song and X.W. Sun

Analysis and Modeling of Error Sources for Spiral Bevel Gear Honing Machine Based on

Multi-Body System Theory

G.Z. Zhang, J. Han and Y.Y. Liu

Optimization Method of the Rubber Elastic Element Structure Based on the Vibrational

Power Flow

W.W. Liu, J.J. Lou and H.P. Wu

Transmission Study on Dynamic Characteristics of Front Suspension LCA Bushing

L.E. Peng and R. Guo

The Study on Experimental Modal Analysis of High-Speed Rotational Shaft

J. Zhao and J.C. Yuan

Modal Experiment and Analysis of Needle-Punching Machine

Z.L. Tang and J.C. Yuan

The Performance Study of Three-Ring Gear Reducer

Y.K. Liu and Y.L. Wei

Influence of Top-Structure Form of Tower Crane on the Factor for Hoisting a Grounded

Load

Y.J. Xia, W.M. Mei and Q. Miao

Research on the Dynamic Characteristic of the Bogie in Dynamic Track Stabilizer on

Working Conditions

L.H. Wang, G.W. Liu and Y.Y. Huang

Dynamic Analysis of a Free-Free Beam

G.C. Han, Y.H. Wu, F.G. Bian and C. Liu

Research on Involute Master Measuring Apparatus

Q. Liu, Y. Ma, S.Y. Ling and Q.M. Wang

Dynamic Analysis for New Low-Speed Motor with Interior Pushrod Harmonic

Transmission Device

X.L. Yang, J.F. Liu, J.C. Zou and W. Ding

Methods for Determining the Dynamic Load of the Shipbuilding Gantry Crane

X.Y. Qian, C.B. Yin and F. Ma 
Distribution on Transmission Ratio of Cylindrical Gear Reducer

L.L. Zhu and G.X. Wang

\section{Chapter 8: Fluid Power Transmission and Control}

The Electro-Hydraulic Proportional Technology-Based Experimental Research into Gradually Pressurization System on Cotton Lap of Roll Machine

J.Q. Yu and J.C. Yuan

Finite Element Stress Analysis of Intersection Region of Nozzle and Blind Flange

J.H. Dong and B.J. Gao

Research on Optimization of Flow Field in 60t Tow-Strand Tundish by Hydraulic Model

J.J. Zhang, W.F. Gao and Z.G. Peng

Design and Analysis of Hydro-Viscous Winch Hydraulic System

Q.R. Meng, S.F. Lin and J. Wang

Hybrid Excavator Test Bed Hydraulic Load System Design

Z.H. Huang, H.W. Gao and Y. Xie

Research on Pneumatic Performance of Aero-Engine Blades through Function Method

W.S. Liu, Y. Sun, G.D. Shi and X.L. Liu

Study on De-Icing Fluid Pump Station's Flow Pulsation Suspension Methods

L.W. Wang, Y.S. Long and Z.W. Xing

Simulation of the HCCI Combustion Based on Single-Zone Combustion Model

Y.S. Jin, J.S. Lin and Z.S. Yan

Design and Implementation of the Integrated Test Platform for the Hydraulic Components

Z.H. Liu, Q.L. Zeng, C.L. Wang and H.X. Kang

Prediction Model of Control Valve Characteristics

Y.D. Xie, Y.J. Liu and Y. Wang

Numerical Simulation of Convection Heat Transfer in a Plate Channel with Sintered

Copper Porous Ribs

X.W. Lu, D.Z. Yang, W.J. Cao and Z.Y. Zhou

Theoretical Study of Transmissivity of Electromagnetic Wave in Magnetorheological Fluids

Y.Q. Wan, J.J. Fan and N.H. Yu

Research on Maximum Wind Energy Capturing of DFIG

H.H. Song and D. Tian

The Research of Internal Fluid State Influence in the Divergency of the Straight Cone-

Shape Draft Tube

Y. Lin, S.R. Han and D.C. Zhang

Fluid Field Analysis for Cyclone Separator Used on Grain Cleaning

L.X. Geng, L.J. Zhang and Q.X. Shi

Impeller Finite Element Analysis of Extractable Explosion-Proof Contra-Rotating Axial Fan for Mine Local Ventilation FBDC

Q.D. He, W.Q. Yu and S.F. Xiao

\section{Chapter 9: Mechatronics}

A Linear Macro/Micro Platform Design Based on FEM Simulation

L.F. Zhang, Z.L. Long, J.W. Fan, Z.C. Wang and J.Z. Yang

The Effect of Electrode's Material on Immobilization of Sulfite Oxidase Enzyme in

Construction of Sulfite Biosensors

A. Ghoseyri, A. Farahbakhsh, S. Khakpur and N. Hosseinfakhrabadi

A Human Half-Top Kinematic Motion Tracking System Based on Disparity Information of Stereo Camera

Y. Kim and S. Jun

Map Matching-Aided In-Motion SINS Initial Alignment

G.W. Zhang, J.B. Chen, C.L. Song and T.T. Wang

Modeling and Design of 3D Visualization on Giant Magnetostrictive Actuator

F. Zeng, J.J. Lou and S.J. Zhu 
A DSP-Based Control System for Precision Variable Rate Fertilization

X.Y. Tang, Y.Z. Chen, Y.K. Peng, X. Wang, Y. Xu, W.L. Yang and W. Wang

1408

Design of a Type of Cleaning Robot System

H. Peng and Z.C. Huang

1415

Analysis of the Biomechanics of the Fingers in Different Writing Stances

M.C. Tsai and S.C. Huang

Modeling of Five-Axis Linkage WEDM for Complex Curved Surface and its Simulation

X.R. Wang, P. Wang, Y.C. Cui and T. Han

The Study of 3-D Magnetic Field Finite Element Analysis for Giant Magnetostrictive

Actuator

F. Zhang, Z.X. Ma and S. Gao

Development of a Precision Micro-Assembly Machine for ICF Targets

W.R. Wu, D.H. Yu, L. Zhang, Z.R. Qiu and X.H. Huang

Development of Integrated Testing Instrument for Mechatronic System

B.L. Liu and L. Lei

1436

High-Temperature Capacitive Mode Pressure Sensor Based on SiC

H.Y. Yu, H.J. Lv, W.Z. Song, Z.B. Yang and M.H. Pang

Characteristics Ansys of Hydraulic Cushion for High-Speed \& High-Precision CNC Lathe

L.P. Liu, Q.Q. Gao and G.H. Deng

Optimization Problem Research for Machining Accuracy and Cost of CNC Lathe Based on Adaptive Particle Swarm Optimization

W.W. Liu and Y. Zheng

The Navigation and Positioning Method of Active plus Passive Ultrasound-Guided Robot

for Liver Cancer Coagulation Therapy

Y.Y. Cao, B.J. Qi, S.X. Wang and W.T. Cui

Sensitivity Analysis and Numerical Simulation of the Planar Mechanism Kinematic

Accuracy

R.J. Zhang, Q.X. Jia, L. Meng and J.W. Qiu

The Kinematic Modeling of a 2-DOF Rotational Parallel Fixture

S.L. Cai, W.T. Huang and L.B. Peng

Design and Realization of Helical Rotor NC Automatic Programming System

F. Chen, L.Y. Gu, Y. Yang and C.Y. Jia

Design of AMT Hydaulic Shift System Based on the Logical-Shift Formula

T. Mei and J.J. Li

Fuzzy Adaptive Terminal Sliding Mode Control for Attitude of Flapping Wing Micro Aerial Vehicle

W.H. Lu, S.B. Hu, J. Wei and D.M. Cao

Novel Compensator for Aircraft Electromechanical Actuator

N. Wang and Y.J. Zhou

Research on Magneto-Rheological Torque Servo Devices

G.F. Li, M.Z. Han, C.Y. Shan, J. Liu and J.X. Yang

Study on Tilt Properties of Orifice-Compensated Aerostatic Thrust Bearings

L. Wei and M.M. Deng

Research on the Internal Model Decoupling Control of High Speed Spindle

Y.S. Li, J. Meng and Y. He

Path Recognition Method for Vision Navigation of Tobacco Harvester

Y. Li, Z.X. Guo and W.S. Wei

Research of CNC Automatic Programming Method Based on Process Database

J.H. Tao, X.J. Fei, M.Y. Zhu, X.C. Liu and H. Liu

Error Analysis of a 2-PRS/2-UPS 4-DOF Parallel Platform

S.L. Cai, L.B. Peng and W.T. Huang

Dynamic Analysis of Key Parts of CNC Milling Machine Based on FEM

W. Cong, Z.Y. Zhang, J. Li and E.X. Han

Finite Element Analysis of Milling Head Box of CNC Machine Tool

L. Sun and X. Wang

Statics Analysis for the Crossbeam of Large Gantry CNC Machine under Six Working 
Automobile Frame Side Rail Detection System Based on Machine Vision

Y.Z. Men, H.B. Yu, H. Wang, J.G. Gao and X. Pan

A Practical Algorithm for Ball-End Mill Using a Five-Axis CNC Grinding Machine

X.J. Sun, F. Tang and X.H. Wang

The Application of PLC in the Stepper Motor Closed-Loop Control System Design

X.Y. Wang

Dynamic Analysis and Structure Improvements on Machine Tool Bed

L. Sun, M.H. Wang, B.F. Shan, J.L. Bai and H. Zhou

\section{Chapter 10: Industrial Robotics}

Structural Design of the Robot Arm for Massage Based on the Chain Drive

Z.L. Wang, Q. Liang and B.C. Zhang

Temperature Uniformity Control in the Low Pressure Process Champer of the IC

\section{Equipment}

H. Huang, T.N. Yang, C.M. Li, Q.L. Zhang and Z.D. Huang

Study on Two-Step Method for Robot Dynamics Parameters Calibration

Q.X. Jia, T. Li and G. Chen

The Path Optimization of Spray Painting Robot for Two Path Pattern

$\mathrm{K}$. Teng and Y. Zeng

Analyzing Moving Character of a Novel Parallel Mechanism

H.J. San, Y.M. Wang and J.X. Liu

Forward and Inverse Position Solution Analysis of 2UPR/1SPR 3-DOF Parallel Mechanism H.J. San, Y.M. Wang and J.X. Liu

A Hardware \& Software System for Unmanned Ground Vehicle Control with Robotic Arm

\& Color Detection

M.S. Rahman, M.S.U. Chowdhury, M.A. Wazed and M.M. Roshid

Robust Adaptive Sliding Mode Synchronous Control for a Planar Redundantly Actuated

\section{Parallel Manipulator}

Y. Long and X.J. Yang

Research on Pneumatic Control System of Box Unfolding and Closing Mechanism of

Horizontal Type Boxing Line

C.W. Chai and J.F. Cai

Path Planning with Motion Optimization for Car Body-in-White Industrial Robot

Applications

P. Božek and K. Trnka

Industrial Robot Control Using Inertial Navigation System

T. Pintér and P. Božek

Application of Optimized BPNN Based on QGA in PID Control of Coal Mine Detection Robots

Y.Y. He and Z.G. Niu

An Introduction to Parallel Robot Mechanism

Z.Y. Xue

Ant Colony Optimization Based on Local Optima Breaking Mechanism for Unmanned Vehicle Path Planning in Cross-Country Environment

M.Y. Feng, H. Li, Y. Yuan and J. Cao

Study on Genetic Fuzzy Wavelet Neural Network Controller of Robotic Manipulator

Y.L. Wang and D.Y. Wang

A New Design of Programmable Multi-Axis Controller

Y.Z. Hu and Q.Z. Zhu

A Robot Vision System in ABU Robocon Contest: Visual Servoing Navigation and Object Tracking

X.H. Li, P. Zhang and S.N. Lin

\section{Chapter 11: Control Technologies and Intelligent Systems}


Duffing Chaotic System Stability Control Based on Sliding Mode Control

D. Ma

An Intelligent Water-Saving System

Y.P. Yang and H.H. Weng

Study on Data Detector of Synchro-Self-Shifting Clutch on Combined Diesel or Gas

Turbine Power Plant

Y. Tian, K.L. Wang, Y.F. Zhang and S.Y. Li

The PLC Control System of Box Processing Combined Machine Tool

L.Y. Li

Parameterization of Emotion Expression through Robot's Body Language

T. Sapsaman and T. Benjawilaikul

The Effect of Hexa-Orientation Press Control System Development on Diamond Material

Grade

H.Y. Hua and Z. Zhang

Multi-Echelon Integrated Inventory Control Strategy of Equipment Spare Parts

H.Q. Gu, C. Zhang and Q. Shi

Research on Vacuum Consumable Arc Remelting Furnace Control System with Drop Short Pulses Testing

G.Y. Lv and S.X. Hu

A System of Multistep Self-Learning Forecast and its Application on Oil Refining Industry

J. Chen

Application of Critical-Siphon Theory to Fastest Deadlock Controller for a Class of Flexible Manufacturing Systems

J.K. Chiang and D.Y. Chao

Remote Monitoring System on Mining Visualization

Y. Yang, Y.L. Li and J. Li

The Analysis of Soft Starting System of Brushless Excitation Synchronous Motor

X.Z. Yang and G.G. Cheng

Based on Adaptive Control in the Process of the Liquid Level Instrumentation Control

System Design

M.M. Cai

The Design of AGV Control System and its Application in Printing Center

P. Zhang

An Exception Handling Approach for Service-Based Business Processes

Z.M. Shang

The Research on the Intelligent Control of Geographic Information System Design to

Agricultural Production

S.R. Wang, J.S. Zhao and S.Z. Lei

The Vehicles ESP Safe Test System Based on Aid Wheels Breaking Control Vehicle System

L. Zhang, G.Y. Wang, F.Z. Yu and Z.F. Zhang

Design and Implementation of Remote Monitoring System for UPS in Unattended

Observation Station

X.F. Tian, X. Zhang and L.L. Zhao

Quantum Artificial Bee Colony Algorithm for Knapsack Problem

Z. Liu and Y.A. Hu

Research on Control Technology of Hydro-Viscous Winch

Q.R. Meng, J. Wang and S.F. Lin

A Chaotic Cellular Neural Network System Research and Implementation Based on FPGA

Z.P. Chen, P.F. Cai and E.Z. Dong

\section{Chapter 11: Control Technologies and Intelligent Systems}

Research on Cogent Automatic Fingerprint Identification System

R. Zhang and F. Wang

An Improved Fast Intelligent Tracking Algorithm with the Gain Adjustable

D.S. Si, X.X. Wang and C. Chen

The Research and Design of Smart Home Based on Virtual Reality Technology

K. Yang 
Development of Full-Automatic Flap Disc Production Machine Based on PLC Control System

D.H. Tang, W.J. Feng and D.Y. Luo

Research on Influencing Spreading Model of Road Congestion Based on Traffic Flow and Cellular Automata Approaches

Y.Z. Men, H.B. Yu, X.S. Li, H. Wang and L. Xu

Pole-Placement for Multi-Input Linear Systems by State Feedback or State-Derivative

Feedback

Z.H. Gao and X.C. Ye

The Design of the Monitoring System Based on Marine Environment Buoy

X.H. Kuang, Z.Y. Wang, C. Yang, H.B. Huo and Y.X. Wu

Automatic Liquid Level Detection System Based on LabVIEW

L. Yu, W.N. Liu and H.H. Wu

A New Intelligent Device Used for Monitoring Environment Safety

C.J. Wang, Y.Z. Liu and L. Ma

Quasi-Likelihood Deconvolution of Non-Gaussian Non-Invertible Moving Average Model M.S. Zhang and J. Huang

The Flow Ratio Process Control System Design Based on Improved PID Algorithm

D.Y. Luo, Y.F. Chen, P. Wang and F. You

Research of Coke Rate Prediction of Blast Furnace Based on Operative Characteristics of Auxiliary Resources

Y.H. Wang, H. Zhang, Z.G. Jiang and G. Zhao

Design of Chemical Water Treatment Control System Based on Quantum PLC

Z.Y.Ye

Research on Intelligent Elevator Control System

X.M. Jiang, Z.X. Hua and Y.N. Rui

Application of the PID Control in Mine Calorific Value Regulating System Based on PLC

X.M. Liu and S.Q. Wang

Identification and Control Design of Fuzzy Takagi-Sugeno Model for Pressure Process Rig A. Subiantoro, F. Yusivar, B. Budiardjo and M.I. Al-Hamid

A Merging Method for Siphon-Based FMS Maximally Permissive Control with Simple

Structures

D.Y. Chao and Y.L. Pan

The Application of Fuzzy Smith-PID Controller on Geothermal Air Conditioning System

L. Li and L. Ai-Lian

Research on Automatic Testing System of Vehicles Steering Angle

H.D. Fu and Z.Z. Wang

Improvement of Set-Covering Weighted Control Model of $S^{3} P R$

D.Y. Chao, Y.N. Lien, J.T. Chen and Y.Y. Shih

Research and Application of Automation Controlling System for Plate Ultra Fast Cooling Process

X.L. Chen, B.X. Wang, Y. Tian, G. Yuan, Z.D. Wang and G.D. Wang

Structures for Weakly Dependent Siphons of $S^{3} P R$

D.Y. Chao and J.T. Chen

Stability Analysis of Quantized Feedback Control System

D.S. Luo, X.K. Hu and Y.W. Feng

Intelligent Algorithm in Automatic Fire Alarm Application

Y.Q. Wang, Y.W. Wang, C.M. Pei, X.Q. Yang and H.R. Ye

The Design of Dynamic Response System Based on Digital Emergency Plan

W.D. Huang, B.L. Ding and L. Yan

Parallel PSO-Based Optimal Strategy Study of Energy Efficient Operation Control for

Train

$\mathrm{H}$. $\mathrm{Hu}$

The Improvement of Control System of Wind Turbine Gearbox Test Device

X.L. Li, D. Liu and C.X. Wang 
Design of a SoC With High-Speed DDC for Software Radio Receiver

J. Deng, L.T. Liu, Y.J. Li, X.Z. Huang, X. Huang and L.C. Liu

The Application Study of Multifunctional Injuries-Simulating Platform

W.W. Sun, K. Chen, X.H. Xu and M.T. Mi

Multi-Band Antenna of Mobile Handset with Metal Frame for Wireless Communication

L.B. Kong and S.S. Zhong

Spacial Filter of Weighting Method Based on Spectrum Analyse

X.M. Li, G.M. Huang and D. Xia

One Kind of Study of the Even Charge-up Method of Intelligence for Common Storage Battery Group of UPS

H.N. Yu

Experimental Analysis on Initial Arc Column Voltage Gradient in Fuse Filled with Silica Sand

Y.Y. Xiao, J.W. Zhuang, B. Chen and J. Wu

A Effective Equalization Based on Multi-Mode for Series Grouped Battery Strings

S.M. Zhang and L. Yanig

Design and Implementation of Robot Soccer Communication Protocol Based on Ant Colony

Algorithm

Y.L. Liu and Z.Z. Chen

Design of the Equalizing Charge Circuit Based on Bidirectional Energy Transfer

H.J. Liang, Y. Zeng, K.P. Xu, Z.W. He and M.Y. Gao

A Novel Three-Port Combiner Based on Coaxial Cavity

S.N. Zhang, Q. Ye and C.W. Luo

Development of Uphole Monitor for MWD in Underground Directional Drilling in

Coalmine

L.P. Wang, J. Gao, J.M. Zhang and Z.J. Shi

An Opto-Electronic Image Sensor Using for Low-Light-Level in Neutron Digital

Radiography(n-DR)

A.M. Zhang, B. Wei, P. Feng, D.L. Mi and Y. Ren

1934

Application of Kalman Filter in SOC Estimation of Power Lithium-Ion Battery

C. Zhao and X.K. Chen

Poly-NiO/Nb:SrTiO 3 Based Resistive Switching Device for Nonvolatile Random Access

Memory

C. Hu and Y.D. Zhu

Design of Counting Device for Contact IC Module

L.L. Wang

The Improved Design of Engine Ignition System

J. Zhao, T. Zhang, J.X. Su and G.M. Luo

A Parallel Space-Time Block Code Based Transmission Scheme

F. Hu, L.B. Jin and J.Z. Li

Research for Biofouling Detection Based on Optical Fiber Self-Referencing Technique and ANN

H.P. Ma, Y.B. Guo, Y.Q. Jin and F. Yuan

Synchronization and Anti-Synchronization of the Chaotic Modified Chua's Circuits via a Same Controller

J.C. Leng and R.W. Guo

Research on UCAV Communication Data Link Capability Increasing Scheme

L. Deng, X.C. Zhou, D.W. Ma and H.J. Zhai

On Application of LDPC Coded Modulation in Optical Fiber Communication

Z.X. Wang and P.X. Wang

Design and Implementation of Radio Spreading-Sequences Beacon Based on Quadrature Frequency-Conversion

J. Xue, J.H. Zou, Y.L. Zhang and X.B. Fang

Design of High-Speed Remote Image Data Storage Memory Based on LVDS

H.X. Zhang, Z. Guo and Y. Ye

Polarization Changes of Elliptically Polarized Laser Beams Propagating in Slant Path through Turbulent Atmosphere

M. Gao, W.N. Nan and H. Lv 
The Research and Analysis about Attenuation Characteristics of Wireless Signal in Limited Space

J. Ma and X. Ying

The Intelligent Design of Solar LED Street Lamps Based on MCU

L.M. Li, L. Zhang and Y.F. Zhang

Design of Automobile Exhaust Wireless Monitor System Based on GPRS/GSM/GPS

Z.Z. Ye, J. Yan, F. Lin, Y.L. Zhang and H.Y. Chen

Design of Azimuth-Sign Wireless Autonomous Positioning System

G.F. Pan, J. Wang, J. Xue, Y.L. Zhang and S. Liang

A Highly Directional Light Emitting Diode Light Guide Bar Based on Concave V-Grooves C.F. Chen, B.H. Lin and S.H. Kuo

A Low-Distortion Single Fingerprint Acquisition Optical System

Z.M. Wu, X.P. Yang, H.B. Xie, Z.H. Chen, F. Li, B. Li and L.L. Cao

The Anomalous Threshold Voltage Prediction by Grey Model GM(1,1) for Submicron MOSFETs

S.L. Chen and D.Y. Shu

The Light Extraction Efficiency Enhancement in Organic Light-Emitting Diodes with

Substrate Modifications

C. Wang, J. Wang, K. Yuan and L. Yu

High Efficiency Performance of Stack-Gate 0.35um P-Channel Flash EPROMs

S.L. Chen and D.J. Tseng

Three Dimension Thermal and Mechanical Simulation of Microbolometer to Detect

Terahertz Wave

L. Yu, J. Wang, K. Yuan and C. Wang

Simultaneous Synchronization and Anti-Synchronization of the Two Identical BVP

Oscillators

J.C. Leng and R.W. Guo

A Mobile Computing SoC Design

X.W. Liu and L.M. Liu

Design and Simulation of High Gain X-Band Horn Antenna for Calibration

Y.L. Zhang, G.F. Pan, J. Xue, Y. Xie and S. Liang

The Special Research on a Low Noise Amplifier

X. Yin, Y. Yao and J.L. Jia

Use of the Fuzzy-Based Taguchi Method for Improving the Yield of BGA Packaging

K.H. Hsien and S.C. Huang

\section{Chapter 13: Embedded System}

The Contactless Card Reader Based on Microcontrollers

X.W. Liu and L.M. Liu

The STM32 and Programmable Power Supply Communication in the ELID Grinding Dynamic Control System

Y.Q. Zhu, Z.F. Hu and B.J. Ma

Embedded Measurement Platform Design for Mine's Dynamic Weighing Bridge

C.X. Zheng and J. Chen

The Development and Application of the Basic Functions of the EMS of Four-Cylinder

Gasoline Engine

Y.J. He, Y. Wang, F.Y. Song, B. Hong and X.L. Li

The IP Design for a Customized Mobile SoC

X.W. Liu and L.M. Liu

Embedded Systems to Build Modern Automation and Manufacture

X.W. Liu and L.M. Liu

An FPGA Based Frame Rate Enhancer for LCD Display in Embedded Systems

K.P. Xu, J.Y. Huang, H.J. Liang, Z.W. He and M.Y. Gao

Study of Embedded Power Environment Remote Video Monitoring System

Y.Q. Wang, Y. Hu, X.Q. Yang, H.R. Ye and C.M. Pei 


\section{Chapter 14: Signal and Intelligent Information Processing}

Signal Separation Based on Focused Neural Network Filter

X.M. Li and J.M. Lv

Adaptive Reconstruction Based on Romp Algorithm

X.H. Xu and D.F. Chen

Moving Target Detection Based on Principle of Connectivity and Texture Gradient

M. Huang, Y. Zhang, G. Chen and G.F. Yang

Shadow Detecting and Shadow Interpolation Algorithm for InSAS

S. Zhang, M. Chen and J.S. Tang

A Robust and Rapid Image Preprocessing Method for Finger Vein

J.B. Xie, T. Liu, Z.Z. Huang, P.Q. Li and W. Yan

2126

Weight to Vision Neural Network Information Processing Influence Research

C.H. Yin, J.W. Chen and L. Chen

Particle Swarm Optimization Least Square Support Machine Based Missing Data

Imputation Algorithm in Wireless Sensor Network for Nuclear Power Plant's

Environmental Radiation Monitor

S. Gao, Y.G. Tang and X. Qu

Research on the Edge Detection Method of the Rice Leaves Image Based on Phase Consistency under the Complex Environment

L.B. Liu, C.J. Zhao, H.R. Wu and R.H. Gao

A Hybrid Method to Search the Optimal Hamiltonian Circuit

Y. Wang, W. He and D. Tian

Morphological Reconstruction Based Segmentation of Lung Fields on Digital Radiographs

B.Y. Zhu and H. Chen

Coordination Method on Cloud Computing Clusters

$\mathrm{Z}$. Xu

The Method of Feature Extraction of Weak Multi-Frequency Signals Based on the Array of Modulated Stochastic Resonance

S.L. Tu, Z.Y. Wu and Z.Y. Wu

The Fusion Process of RS(Remote Sensing) Data Based on Wavelet Neural Network

L.M. Zhang and X.Q. Zhao

Research on the Optimized Algorithms on Neural Network

X.Q. $\mathrm{Wu}$

Classification of Single Cereal Grain Kernel Using Shape Parameters Based on Machine

Vision

L.L. Wu, J. Wu, Y.X. Wen, L.R. Xiong and Y. Zheng

Detection for Corn/Weed Images Using Moment Invariants by BPNN Classifier

L.L. Wu, J. Wu, Y.X. Wen, H. Peng and Z.H. Zhu

On Implementation of Software Acoustic Cancellation

Y.F. Wang, Y.H. Lv and H.Z. Cai

A New Variable Step Size LMS Adaptive Filtering Algorithm and its Analysis

W.J. Cai

Low SNR Singal Recovery System Based on Stochastic Resonance

H. Deng, H. Liu, B.T. Song, H. Zhang and S. Yang

Research on Improved Image Enhancement Algorithm Based on Fuzzy Set

X.W. Liu and C.Y. Liu

A Novel Method to Estimate the Unknown Mixing-Matrix for Blind Source Separation

N. Chen and H.Y. Zhang

An Information Fusion Algorithm Based on Dopplerlet-Hough Transformation

M.H. Deng, Q.S. Zeng and L.Y. Zhang

Study of Adaptive Chaos Embedded Particle Swarm Optimization Algorithm

R. Hua, D.J. Chen and Y.Z. Ye

Radio Channel Research in Coal Mine Laneways

Y. Yang, Y.L. Li and J. Li 
Yawning Detection Based on Mouth Feature Points Curve Fitting

W.Y. Ding, L. Zhang and Y.H. Chen

Cartoon Avatar Processing Based on Image Edge Detection

Y.S. Zhang, L.M. Sun, X.H. Shen, Y. Zhou, Y. Li and W. Wang

2232

Analysis of Airplane Timing Equipment's Automatic Test Based on ATS Platform

X.X. Zhan, S.Y. Hao, J.F. Si, Y.F. Zhang and C.F. Yu

2236

Image Texture Feature Extraction \& Recognition of Chinese Herbal Medicine Based on

Gray Level Co-Occurrence Matrix

Q. Liu, X.P. Liu, L.J. Zhang and L.M. Zhao

Classification of Biological Spectrum Based on Principal Component Cluster Analysis

L.S. Zhang and A.J. Shi

Image Restoration Based on Improved PSO Algorithm

Z.Y. Ye

Convergence of a Class of Nonorthogonal Wavelet

S.G. Zhao

Research on a Kind of Distribution Selection Method for Right Censored Data Based on Data Expansion Algorithm

J.H. Wu, H.B. Liu, Y.D. Wang and J.W. Lei

Improved Vision Based Driving Space Analysis by Condensation of Image Data

Y.F. Mao, H. Wiedmann and M. Chen

Application of the Compound Model of BP Neural Networks and Wavelet Transform in Image Definition Identification

R.K. Gong, Y.N. Zhang, C.H. Wang and L.J. Zhao

An EEG Analysis Research For Epileptics Using Probabilistic Neural Network

X. Xu, J. Song, Y.T. Hu, W.X. Shi and X. Zhu

Object-Oriented Zhangjiangkou Mangrove Communities Classification Using QuickBird Imagery

D.S. Zhang, L.X. Cong, Z.Q. Wang, H. Chen and F. Wang

Applying Data Mining Methods to Structural Identification

M. Horalova Kalinova, G. Michalconok and D. Gabriska

Inter-Harmonic Detection Based on AR Model Spectral Estimation and Nonlinear

Optimization

H.Q. Zhang, R. Liu, Z.H. Fu and K. Zheng

\section{Chapter 15: Software and Computer in Research and Engineering Solutions}

Ranking Algorithms for Keyword Search over Relational Databases

C. Wang, J. Ding and B. Hu

The Application of Bezier Curves about the Visualization of the Threaded Binary Tree

X.B. Yang and B.Z. Chen

Research and Design of the Automobile OBD Data State Monitoring System Based on the Android Phones

W.D. Huang, Y. Zhang and J.H. Liu

Fidelity Evaluation of Bridge-Type Grab Ship-Unloader Visual Simulation

H.J. Lu, D.F. Chang and X. Liu

Risk Assessment of Smart Grid Cyber Security Based on Multi-Level Fuzzy Comprehensive Evaluation Method

K.W. Zhang

Scene Simulation of UUV's Glide Motion Based on Creator and Vega Prime

P. Zhang, B.W. Song and X.X. Du

Research on the Die Steel Cutting Simulation System Based on Intelligent Layout Algorithm M.J. Zhou, T.J. Ma, X.J. Zhao and S. Li

Analysis on A 1-out-n Security Protocol Based on Threshold Idea

L. Yu and J.Y. Ye

The Study of Military Conceptual Model Based on Tactical Decision-Making Simulation

J.G. Liu and Z.F. Wu 
Managing Emergency Material Distribution Knowledge Using Ontology-Based Modeling for Emergency Distribution Decision

L. Zhang, D.L. Jiang, Y.R. Ju, Q.Z. Wang and P.P. Li

Security Design of Web-Based Information Integrated System

T. Chen and H.P. Pan

The Application of Improved Color Petri Net in Hardware Design

P. Liu, Y.Z. Liu and C.J. Wang

An Approach of Web Service Discovery and Composition Based on Logic Petri Nets

S.Y. Deng and Y.Y. Du

ZigBee Technology Application in Disaster Rescue

F. Jiang and W. Zhao

Parallel Computing Application in Rectangle Packing Problem

X.C. Wang and Z.X. Jin

The Research of Railway Passenger Flow Prediction Model Based on BP Neural Network Y. Wang, D. Zheng, S.M. Luo, D.M. Zhan and P. Nie

On Visualization of Journals Reference Network Based on Force-Directed Layout

Algorithms

X.Y. Du

The Design of the Sensor Node of IOT Based on SIM20

X.H. Kuang, Z.Y. Yao, H.B. Huo, J.J. Li and Y.X. Wu

The Research and Implementation of Geospatial Data Management Based on ArcGIS

Service

F. Zheng, H.R. Lu, Y. An and L.J. Guo

Building Bridges among Local Area Networks

J. Chen

Analysis on Internet Attack and Security

J. Chen

Objects Collision Detection in Virtual Scene

R.G. Zhang, Z.F. Wang, X.J. Liu and K. Liu

Research of Digital Watermarking Algorithm Based on DCT Transform

Y.J. Zhang

Weapon-Target Assignment Problem in the Warship Fleet Based on Fast and Elitist NonDominated Sorting Genetic Algorithm

X.L. Chen and S. Shen

Early-Warning Model for Tourism Environment Carrying Capacity in Scenic Spots Based on Fuzzy Inference

X.P. Yang and E.C. Li

Simulation and Analysis of AUV's Hydrodynamics when Moving in the Near-Seabed

F.Z. Zhao, B.W. Song and X.X. Du

Research of Digital Simulating Model of Assembling Shunt Capacitor

J.J. Xiong, M. Sun, R.X. Fan, T. Ding and L.J. Qian

A B/S-Based Multi-Server Framework for Knowledge Component Implementation

Z.J. Ming, J. Hao, Y. Yan and G.X. Wang

Numerical Simulation on the Stress and Strain of Lining Structure with Double Shield

Tunneling Construction

F. Wang and T.J. Cui

A Collaborative Filtering Recommendation Method Based on Item Category

W.B. Deng and J. Liu

The Vestibular System Modeling in the Head and Eye Movement Research

C.Y. Wang, B. Yao, H.Z. Bi and H.B. Jia

Design and Implementation of Module Hot-Plugging in Equipment Management Platform S.R. Wang, D.E. Meng and J.S. Zhao

A Quantum-Behaved Particle Swarm Algorithm Combined with Chaotic Mutation

X.R. Li and Y.X. Jin

The Design and Development of Learning Log Management System for C Language Web Classroom 
Study on Custom Service Combination Based on BPEL

Y.J. Cai and Z. Le

Applying RBF Neural Networks and Genetic Algorithms to Nonlinear System Optimization

H.F. Wang and X.A. Xu

Flow and Density Difference Lattice Model and its Numerical Simulations Analysis

H. Dai, Z.Z. Yuan and J.F. Tian

Study on Network Emergency Evaluation with Web-Based Information

C.M. Wang

2466

An Intelligent Method Optimizing BP Neural Network Model

H.H. Xing and H.Y. Lin

Error Resilience Scheme for Real-Time Video

X.W. Ding, Y.G. Dagnew and A.P. Yang

A Framework for Filtrating Software Measures in Software Measurement Process

J.Z. Wang and J.J. Ding

Research and Implementation on XML-Based Data Exchange Platform

L. Zhao, F. Deng and S.F. Du

The Research and Application of Sorting Algorithm in Aircraft Scheduling Problem

H.R. Xu, L.H. Yang, Q. Huang and J. Wang

Random Choice of Logistics Distribution Route Based on Dynamic Programming

H.J. Zhao and D.M. Huang

Research on Particle Swarm Optimization for Protein Structure Prediction

S.G. Wang, F.J. Wang, S.F. Jiang and H.J. Zhang

On the Construction of Safety Running and Management Systems for Chinese E-

Government System

D.P. Zhao and R.X. Zhang

Numerical Simulation of Overpressure about Muzzle Blast Flowfield

Z.X. Guo, Y.T. Pan, K.W. Li and H.Y. Zhang

Application of Visualization and GIS Techniques in Water Conservancy Works

N. Xie and Z. Yang

Efficient Front-End Cache for XEN Virtual Block Device

X. Mi, W. Ye and A. Liang

Development of Information Management System Used in Laboratory

$\mathrm{Y} . \mathrm{Hu}$

Intelligent Voice Terminal with Image Retrieval Function

Z.X. Wei and J.M. Liang

Information Service: Podcast Course Video-Sharing System, for Example

W.L. Huang and M.S. Chen

Application of Red Spider Software in Multimedia Network Classroom

S.M. Jia, X.L. Dai, A.Y. Chen and X. Zhou

E-Commerce Model Research Based on Cloud Service

D.J. Ma

Slicing Objects Using UML State Diagram

$\mathrm{X}$. Wang, F. Wei and C. Cheng

Traffic Status Prediction and Analysis Based on Mining Frequent Subgraph Patterns

G. Xu, H.H. Jin and J. Liu

Architecture Design of Urban Intelligent Transportation Using Cloud Computing

J.Z. Wang and Z.J. Wang

The Application Research of Private Cloud in the Data Centers Colleges of Universities

X.P. Wang, L.X. Feng and J.D. Zhao

The Research and Application in Intelligent Document Retrieval Based on Text

Quantification and Subject Mapping

Q. Wang, S.N. Qu, T. Du and M.J. Zhang

Research on Evaluation Index System of Multimedia Teaching Software

Y.X. Liu, Z.H. Yuan and W. Shi

Trust Federation of Identity Management in Distributed Environment

D.M. Li, Y.H. Wang and J.Y. Chen 
Study on Teaching Method of Project in the Operating System

L.N. He, G.M. Gu and B. Chen

Study on the Software Trustworthiness Measurement Algorithm Based on the Grey

Relational Analysis

J.F. Yang

Information Hiding of MS-Office Compound Document

G.M. Zhu, X.G. Zhan and X.L. Zhou 


\title{
A Framework for Life Cycle Cost Estimation of a Product Family at the Early Stage of Product Development
}

\author{
Jaya Suteja The ${ }^{1 *, a}$, Prasad KDV Yarlagadda ${ }^{1, b}$, Azharul Karim $^{1, c}$ \\ and Cheng Yan ${ }^{1, d}$ \\ ${ }^{1}$ Science and Engineering Faculty, Queensland University of Technology, Australia \\ ajaya.the@student.qut.edu.au, ’y.prasad@qut.edu.au, cazharul.karim@qut.edu.au,
}

*He is a lecturer at University of Surabaya, Indonesia and is currently on study leave to undertake his PhD at Queensland University of Technology, Australia

Keywords: Life Cycle Cost, Cost Estimation, Product Family, Early Design Stage.

\begin{abstract}
A cost estimation method is required to estimate the life cycle cost of a product family at the early stage of product development in order to evaluate the product family design. There are difficulties with existing cost estimation techniques in estimating the life cycle cost for a product family at the early stage of product development. This paper proposes a framework that combines a knowledge based system and an activity based costing techniques in estimating the life cycle cost of a product family at the early stage of product development. The inputs of the framework are the product family structure and its sub function. The output of the framework is the life cycle cost of a product family that consists of all costs at each product family level and the costs of each product life cycle stage. The proposed framework provides a life cycle cost estimation tool for a product family at the early stage of product development using high level information as its input. The framework makes it possible to estimate the life cycle cost of various product family that use any types of product structure. It provides detailed information related to the activity and resource costs of both parts and products that can assist the designer in analyzing the cost of the product family design. In addition, it can reduce the required amount of information and time to construct the cost estimation system.
\end{abstract}

\section{Introduction}

To provide customized product at reasonable cost in a shorter lead-time, mass customization is the most widely implemented approach. Mass customization is defined by Pine (1993) as variety and customization through flexibility and quick responsiveness [1]. The aim of this approach is to deliver a variety of product that fulfils customer needs while keeping mass production efficiency [2]. However, it is not feasible to develop all product variation because of some of the limitations within and outside the manufacturing companies. Simpson (2004) proposes that an effective means to providing a variety of products in a cost effective way is through a product family design [as cited in 3]. In general, product family is defined as "a group of related products that is derived from a product platform to satisfy a variety of market niches" [4].

To ensure the success of mass customization approach (in this case, designing a product family) in a product development chain, a rapid and accurate cost estimation and control system is needed [5]. The cost estimation system should consider not only pre production and production cost (design, manufacturing, and assembly) but also post production cost (customer use, support, and end of life). Therefore, a cost estimation method is required to estimate the product life cycle cost of the product family at the early stage of product development in order to evaluate the product family design.

Various cost estimation techniques have been suggested to estimate the cost of the product family. However, there are difficulties with these techniques in estimating the life cycle cost for a product family at the early stage of product development. This paper proposes a framework to solve this problem. In the next section, an analysis of various cost estimation techniques for a product family 
and a description of their weaknesses in estimating life cycle cost for a product family at the early stage of product development are provided. In Section 3, a framework to estimate the life cycle cost of the product family is presented. Conclusions are drawn and described in the last section.

\section{Life Cycle Cost Estimation Techniques for a Product Family}

Existing cost estimation techniques can be classified into four classifications, which are intuitive, analogy, parametric, and analytic techniques [6]. Many researchers propose using various analytic techniques in estimating cost of a product family. A cost index structure combined with generative and variant cost estimation methods is proposed by Tu, Xie, \& Fung (2007) to estimate cost in mass customization [5]. The technique covers only production cost and is problematic in estimating post production cost.

Park \& Simpson (2005) develop an activity based costing framework for a product family, which consists of allocation, estimation, and analysis stages [7]. Later, they refine the framework by developing cost modularization in the activity based costing system [3]. Related to the activity based costing technique, Chen \& Wang (2007) propose a generic activity definition in order to simplify and catalyze activities based costing especially in high variety production [8]. To use an activity based costing technique, low level information related to required activities and resources in producing all products should be available. Other research by Johnson \& Kirchain (2010) proposes process based cost modeling as cost modeling methodology to estimate fabrication, assembly, and development costs of the product [9]. Similar to an activity based costing technique, process based cost modeling also requires detailed information in order to estimate the cost.

In general, existing analytic techniques are difficult to implement at the early stage of product development because they require detailed and complete information as their input. Meanwhile, the available information in the early stage of product family development is high level information. This difficulty also is faced in existing parametric techniques because it requires parameters to be identified before performing cost estimation.

To solve the problem, several types of analogy technique are suggested to estimate cost at the early stage of product development. An analogy technique can estimate cost using high level information as the input. Seo, Park, Jang, \& Wallace (2002) develop a cost estimation system that employs artificial neural networks to estimate life cycle cost in conceptual design [10]. Seo, et al. (2002) do not specifically develop cost estimation for a product family but this system can be used to estimate the cost of all product variants of a product family at the early stage of product development. This cost estimation system provides fast estimation but poses difficulties if the product structure changes due to a new design. In addition, an artificial neural network functions as a black box in cost estimation and does not provide detailed information related to various factors and their influence on the cost. Therefore, this system cannot be used in analyzing the cost of a product family and evaluating its design.

Intuitive technique is used by Shehab \& Abdalla (2002) in modeling the cost of a machining component and an injection molding component [11]. In their research, they propose an intelligent knowledge based system with hybrid knowledge representation techniques. Intuitive technique is mostly used to estimate cost for a single part because it requires a large volume of information and extensive time to construct the cost estimation system $[12,13]$.

Accordingly, existing analogy cost estimation techniques can be difficult to use for life cycle cost analysis at the early stage of product development. In addition, they cannot be used if the product family structure changes due to a new design. Furthermore, existing intuitive techniques require much more information and time to construct a cost estimation system for a product family compared to that for a single part because a product family consists of various parts.

As a single technique has difficulties in estimating the life cycle cost of a product family at the early stage of product development, a hybrid technique raises the possibility of solving the problems [14-16]. Liu, Gopalkrishnan, Ng, Song, \& Li (2008) build an intelligent system to estimate the 
product life cycle cost at the early design stage. This research applies activity based costing and machine learning technique to define and estimate various life cycle cost elements [17]. An artificial neural network or support vector regression is applied if available activity and resource information are insufficient. An activity based costing is applied if there are sufficient activity and resource information. This intelligent system can only estimate the cost of a product family that use a certain product structure and it cannot be used to analyze the cost of a product family.

Other existing hybrid technique is proposed by Xu, Chen, \& Xie (2006) [18]. They propose to use case based reasoning to buid a new product model and activity based costing to calculate the life cycle cost of a product. However, the framework cannot be used to estimate the life cycle cost for each product family level (platform, product variant and product family). As a result, the framework cannot be used to analyse the cost of a product family.

\section{Life Cycle Cost Estimation Framework}

According to Park \& Simpson (2008), activity based costing is an appropriate technique to estimate the cost of a product family because it is able to allocate indirect cost more accurately to each product variant in the product family [3]. This ability is important because applying a product family approach increases product variety and production volumes. As a result, overhead cost becomes larger than total production cost and does not proportionally increase with production volumes. However, as described above, an activity based costing technique requires detailed activity and resource information and can be problematic to implement at the early stage of product development. For that reason, a method to provide the required information at the early stage of product development should be developed and then combined with the activity based costing.

This paper proposes a framework that combines a knowledge based system and an activity based costing techniques in estimating the life cycle cost of a product family at the early stage of product development. In this paper, the early stage of product development refers to the stage after product planning and before product embodiment. The framework will apply an expert system and a case base reasoning to solve the problem in generating the required activity and resource information at the early stage of product development. Then, the generated information will be used as an input of the activity based costing technique to estimate the life cycle cost of a product family at the early stage of product development.

The aim of the framework is to provide a tool for estimating the life cycle cost of various product families, which have various types of structure, by using available high level information at the early stage of product development. The inputs of the framework are a product family structure and its sub functions. The sub function is represented by the use of the function taxonomy of Hirtz [19]. The information related to the sub function consists of its type, market segment, input, and output. The type classifies each sub function into a base or variant sub function. The market segment explains its product segment, performance, and production volume. The input and output describe input and output material, energy, motion, and signal of each sub function. Based on the input, the framework will generate life cycle cost information of a product family as its output that consists of all costs at each product family level and the costs of each product life cycle stage (research and development, production, logistic, usage and end of life).

The framework consists of five steps as shown in Figure 1 below. The first step is to retrieve and select a concept that could satisfy each required sub function. First, each sub function is mapped to at least one appropriate concept that can satisfy the sub function and then designers select the best concept for each sub function based on their expertise. Case based reasoning is used to find the appropriate concepts from previously developed concept database. Each selected concept inherits the type and market segment information of the related sub function.

The next step is to break down each selected concept into its assembled parts and to provide information related to the type, market segment, procurement type, design, logistics, physical, after sales and end of life attributes of each assembled part. The type and the market segment information 
of each part are inherited from the related concept. The procurement type determines whether the part will be manufactured inhouse or outsourced. The physical attributes of part could include quantity, material, shape, main dimension, specific features, and required tolerance. The procurement type and the five attributes information are required to generate data on all activities and resources performed at each product life cycle stage. Case based reasoning is used to determine the assembled parts and their related information.

The third step is to generate activity and resource information for each part, which are required or consumed from the design stage up to the end of life stage of product life cycle. The activity information consists of all required activities consumed by each part. The resource information describes all resources consumed by each activity. First, each assembled part is categorized according to its procurement type. The activities and consumed resources information related to the outsourced parts are generated differently compared to the inhouse parts. The activity information of an inhouse part comprises process related and non process related activities. Meanwhile, no manufacturing process activity is required for an outsourced part. Therefore, the activity information of outsourced part comprises only all activities that are not related to the manufacturing process. Then, the process required to manufacture each inhouse part is determined by the use of the expert system. Next, all process related activities for the inhouse part are generated by the use of the case based reasoning. The activity information of non related part is also generated by using case based reasoning. Finally, all resources required in conducting each activity are determined by using case based reasoning. Because a knowledge based system is used to generate general activities and resources information that can be applied to all parts, the amount of information and time in constructing the cost estimation system are not as great as generating cost information for each part.

Next, all activity and resource information required to produce all product variants of the product family are then generated. Product structure that describes the hierarchical relationships of all parts is used to determine the required activities. The sequence of assembly/disassembly process and the parts that are assembled/disassembled are determined by the use of the expert system. Then, all the resources consumed in conducting each activity are generated. This step uses a similar technique to generate activity and resource information for parts. Because the product structure is used as the input, the proposed framework makes it possible to estimate the life cycle cost of the product family that have any types of product structure.

The last step is to calculate the life cycle cost of the product family by the use of an activity based costing. Activities and resources information for a part, operational data (i.e. working days, hours per day, etc.), and financial data (i.e. material cost, labor wage, etc.) are used to calculate the life cycle cost of each part. Parts that require similar activities are grouped and the resources that they consume are identified. Then, the usage of the resources consumed is calculated and summed. The total usage of the resources consumed is used to calculate resource consumption rates. The resource consumption rate is equal to total resource cost divided by the total usage of the resource consumed. Each activity cost of a part can be calculated by multiplying the resource consumption rate with the resource usage of the activity. The life cycle cost of each part can be calculated by adding all costs of the activities consumed by the part and then divide it with the production volume of the part.

Activities and resources information for a product, operational data, and financial data are used to calculate the activity costs for a product. It is similar to calculate the activity costs for a part. The life cycle cost of each product can be calculated by adding all activity costs for a product divided by the production volume of the product and the life cycle cost of all of its parts. The life cycle cost can be calculated for each product family level and for each product life cycle stage.

\section{Conclusions}

The proposed framework provides a life cycle cost estimation tool for a product family at the early stage of product development using high level information as its input. The framework makes it possible to estimate the life cycle cost of various product family that use any types of product 
structure. It provides detailed information related to the activity and resource costs of both parts and products that can assist the designer in analyzing the cost of the product family design. In addition, it can reduce the required amount of information and time to construct the cost estimation system.

By using the proposed framework, manufacturing companies will be able to estimate all costs throughout the product life cycle of all product variants (platform and variants) of various product families, analyze the profitability of a product family design, and perform tradeoffs between the benefit and the cost in designing a product family.

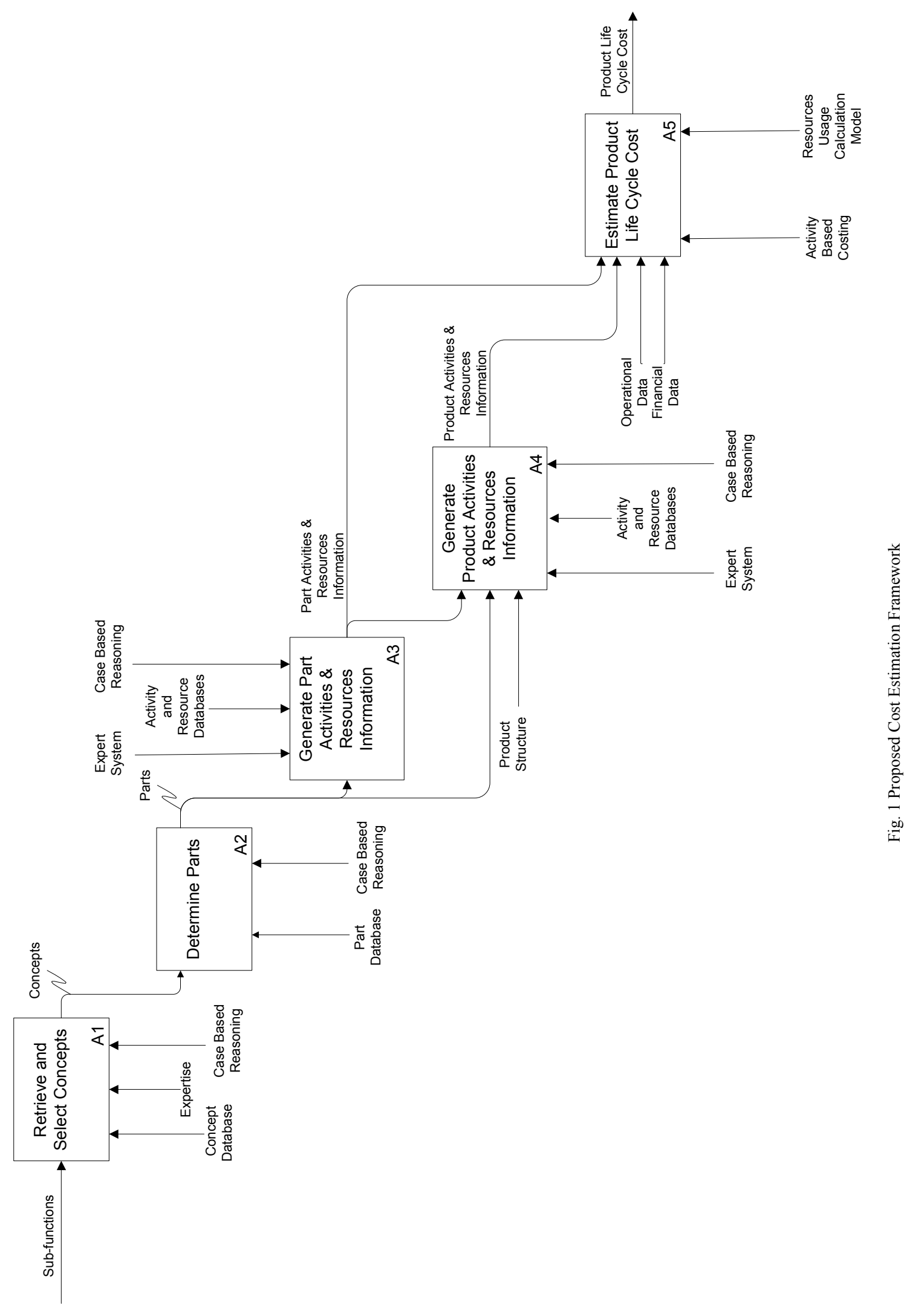




\section{Acknowledgement}

This research was supported by a scholarship from Directorate General for Higher Education, Ministry of Education and Culture, Republic of Indonesia (GL Number: 501/E4.4/K/2011).

\section{References}

[1] B.J. Pine, Mass customization: the new frontier in business competition. (1993), Boston, Mass: Harvard Business School Press.

[2] J. Jiao and M.M. Tseng, A methodology of developing product family architecture for mass customization, Journal of Intelligent Manufacturing. 10(1) (1999) 3-20.

[3] J. Park and T.W. Simpson, Toward an activity-based costing system for product families and product platforms in the early stages of development, International Journal of Production Research. 46(1) (2008) 99-130.

[4] T.W. Simpson, Z. Siddique, and J. Jiao, Product platform and product family design: methods and applications. (2006), New York: Springer-Verlag.

[5] Y.L. Tu, et al., Product development cost estimation in mass customization, IEEE Transactions on Engineering Management. 54(1) (2007) 29-40.

[6] A. Niazi, et al., Product cost estimation: Technique classification and methodology review, Journal of Manufacturing Science and Engineering-Transactions of The ASME. 128(2) (2006) 563-575.

[7] J. Park and T.W. Simpson, Development of a production cost estimation framework to support product family design, International Journal of Production Research. 43(4) (2005) 731-772.

[8] Z. Chen and L. Wang, A generic activity-dictionary-based method for product costing in mass customization, Journal of Manufacturing Technology Management. 18(6) (2007) 678-700.

[9] M.D. Johnson and R. Kirchain, Developing and Assessing Commonality Metrics for Product Families: A Process-Based Cost-Modeling Approach, IEEE Transactions on Engineering Management. 57(4) (2010) 634-648.

[10] K.K. Seo, et al., Approximate Estimation of the Product Life Cycle Cost Using Artificial Neural Networks in Conceptual Design, International Journal of Advanced Manufacturing Technology. 19(6) (2002) 461-471.

[11]E. Shehab and H. Abdalla, An Intelligent Knowledge-Based System for Product Cost Modelling, International Journal of Advanced Manufacturing Technology. 19(1) (2002) 49-65.

[12] H. Wang, X.Y. Ruan, and X.H. Zhou, Research on Injection Mould Intelligent Cost Estimation System and Key Technologies, International Journal of Advanced Manufacturing Technology. 21(3) (2003) 215-222.

[13] K.H. Ko, K. Pochiraju, and S. Manoochehri, An embedded system for knowledge-based cost evaluation of molded parts, Knowledge-Based Systems. 20(3) (2007) 291-299.

[14]F.T.S. Chan, Application of a hybrid case-based reasoning approach in electroplating industry, Expert Systems With Applications. 29(1) (2005) 121-130.

[15]P. Duverlie and J.M. Castelain, Cost Estimation During Design Step: Parametric Method versus Case Based Reasoning Method, International Journal of Advanced Manufacturing Technology. 15(12) (1999) 895-906.

[16]R. Chougule and B. Ravi, Casting cost estimation in an integrated product and process design environment, International Journal of Computer Integrated Manufacturing. 19(7) (2006) 676-688.

[17] H. Liu, et al., An intelligent system for estimating full product life cycle cost at the early design stage, International Journal of Product Lifecycle Management. 3(2/3) (2008) 96-113.

[18] X. Xu, J.L.Q. Chen, and S.Q. Xie, Framework of a Product Lifecycle Costing System, Journal of Computing and Information Science in Engineering. 6(1) (2006) 69.

[19] J. Hirtz, et al., A functional basis for engineering design: Reconciling and evolving previous efforts, Research in Engineering Design. 13(2) (2002) 65-82. 